\title{
When Will We Detect Changes in Short-Duration Precipitation Extremes?
}

\author{
ELIZABETH J. KENDON \\ Met Office Hadley Centre, Exeter, United Kingdom \\ STEPHEN BLENKINSOP AND HAYLEY J. FOWLER \\ School of Engineering, Newcastle University, Newcastle-upon-Tyne, United Kingdom
}

(Manuscript received 27 June 2017, in final form 18 December 2017)

\begin{abstract}
The question of when the influence of climate change on U.K. rainfall extremes may be detected is important from a planning perspective, providing a time scale for necessary climate change adaptation measures. Short-duration intense rainfall is responsible for flash flooding, and several studies have suggested an amplified response to warming for rainfall extremes on hourly and subhourly time scales. However, there are very few studies examining the detection of changes in subdaily rainfall. This is due to the high cost of very high-resolution (kilometer scale) climate models needed to capture hourly rainfall extremes and to a lack of sufficiently long, high-quality, subdaily observational records. Results using output from a $1.5-\mathrm{km}$ climate model over the southern United Kingdom indicate that changes in 10-min and hourly precipitation emerge before changes in daily precipitation. In particular, model results suggest detection times for short-duration rainfall intensity in the 2040s in winter and the 2080s in summer, which are, respectively, 5-10 years and decades earlier than for daily extremes. Results from a new quality-controlled observational dataset of hourly rainfall over the United Kingdom do not show a similar difference between daily and hourly trends. Natural variability appears to dominate current observed trends (including an increase in the intensity of heavy summer rainfall over the last 30 years), with some suggestion of larger daily than hourly trends for recent decades. The expectation of the reverse, namely, larger trends for short-duration rainfall, as the signature of underlying climate change has potentially important implications for detection and attribution studies.
\end{abstract}

\section{Introduction}

Recent U.K. floods (e.g., caused by Storm Angus across the country in November 2016, in the north of the United Kingdom in December 2015, and in Somerset in January 2014) have reinforced the need for the United Kingdom to gain a better understanding of how its exposure to flooding may change in the future with global warming. This is vital so that appropriate levels of resilience and protection can be delivered through river and land management and investment in flood defenses (Cabinet Office and Defra 2016). Short-duration intense rainfall is responsible for flash flooding, important in

\footnotetext{
Supplemental information related to this paper is available at the Journals Online website: https://doi.org/10.1175/JCLI-D-170435.s1.

Corresponding author: Elizabeth Kendon (nee Kennett), elizabeth. kendon@metoffice.gov.uk
}

small, steep catchments and urban areas. Precipitation data at subdaily scales (down to a few minutes) and spatial scales of $1-10 \mathrm{~km}^{2}$ are needed for urban drainage design (Arnbjerg-Nielsen et al. 2013); hence, an understanding of changes in precipitation at these scales is important so urban planners can start accounting for the effects of future climate change. Notable U.K. examples of this type of extreme event were the floods in Boscastle in August 2004 and in Newcastle-upon-Tyne in June 2012 (Archer and Fowler 2018), which caused extensive damage and major disruption.

In the context of climate change, with increasing temperature, the atmosphere is able to hold more moisture, and this is expected to lead to future increases in heavy rainfall intensity (Trenberth et al. 2003). Further, it has recently been argued that observational evidence of the intensification of extreme rainfall is beginning to show consistency with model studies (Fischer and Knutti 2016). The Clausius-Clapeyron (CC) relation suggests that if relative humidity remains 
constant, atmospheric humidity will increase at a rate that follows the saturation vapor pressure dependency on temperature according to the $\mathrm{CC}$ relation-a rate of $\sim 7 \%$ per ${ }^{\circ} \mathrm{C}$ of surface warming (e.g., Allen and Ingram 2002; Pall et al. 2007). This sets a scale for change in precipitation extremes (Trenberth et al. 2003). Several studies have provided observational evidence of a superCC $(2 \times$ CC) relationship for hourly (e.g., Lenderink and van Meijgaard 2008, 2010; Mishra et al. 2012) and subhourly (e.g., Loriaux et al. 2013) extremes, which might suggest an amplified response to warming on these time scales. Such super-CC scaling seems to be a property of convective precipitation (Berg et al. 2013) and may be explained by latent heat released within storms invigorating vertical motion, leading to a greater increase in rainfall intensity. The dependency of extreme U.K. hourly rainfall on temperature has been demonstrated to be consistent with $\mathrm{CC}$ scaling in observations (Blenkinsop et al. 2015) and a high-resolution, convection-permitting climate model (Chan et al. 2016a), but no evidence has been identified of super-CC scaling, including for simulated 10-min extremes (Chan et al. 2016b).

Relatively coarse-resolution projections $(25 \mathrm{~km})$ provided by the U.K. Climate Projections 2009 (UKCP09) (Murphy et al. 2009) suggest that changes in the wettest day of winter ( $\sim 99$ th percentile of daily precipitation) range from zero in parts of Scotland to $+25 \%$ in parts of England (central estimate, 2080s, medium emissions), while changes in the wettest day in summer range from $-12 \%$ in parts of southern England to $+12 \%$ in parts of Scotland. Summer changes, however, are subject to high levels of uncertainty associated with the parameterization of convection in these models. Typically, projected changes in subdaily extremes have been assessed using statistical methods to disaggregate daily precipitation from regional climate models (RCMs). Darch et al. (2016) used a weather generator to provide illustrative results for 10 U.K. sites to show a projected increase in the intensity of short-duration events in winter but a reduction in summer. Again, however, these are associated with high uncertainty due to the underlying climate model resolution and the fact that they do not use climate change information at the subdaily scale. This is being addressed by the new generation of very high-resolution, convection-permitting models (CPMs), which explicitly represent convection without the need for a parameterization scheme. These models are able to more realistically represent convection and to capture hourly rainfall characteristics, including extremes, unlike traditional coarser-resolution climate models (Kendon et al. 2012; Chan et al. 2014b). The first CPM climate change simulations for the southern United Kingdom project an increased intensity of extreme hourly rainfall in summer and almost a fivefold increase in events above $30 \mathrm{~mm} \mathrm{~h}^{-1}$ (a critical accumulation threshold used by the Flood Forecasting Centre to indicate likely flash flooding) (Kendon et al. 2014).

In common with most other parts of the globe, observed long-term variability and detection of trends in U.K. subdaily rainfall have received little study due to the lack of sufficiently long, high-quality records (Westra et al. 2014; Hegerl et al. 2015). Faulkner (1999) produced a relatively simple analysis of changes in U.K. 1-h annual maxima, observing a possible decreasing trend over the twentieth century, but noted that this was potentially subject to inhomogeneities arising from changes in rain gauge type and temporal variations in the observing network. Studies of observed changes in subdaily rainfall have tended to focus on relatively small regions, with exceptions for the United States (Barbero et al. 2017) and Australia (Westra and Sisson 2011), and show inconsistency in their changes, though they generally suggest an increase in intensity (Westra et al. 2014). Historical trends in U.K. daily rainfall have been relatively extensively studied, however, identifying more intense winter rainfall since the 1960s (Osborn et al. 2000; Osborn and Hulme 2002; Maraun et al. 2008), with some evidence of a longer-term trend (Osborn et al. 2000; Simpson and Jones 2014). The contribution to winter rainfall from heavy precipitation events has also increased (Jenkins et al. 2008), while Jones et al. (2013) identify increases in seasonal maxima and estimated return frequencies in winter. In contrast, summer rainfall events have shown little change or declined in intensity, while longer-duration events (multiday) have increased (Fowler and Kilsby 2003a,b; Jones et al. 2013). Simpson and Jones (2014) note that trends in mean and extreme summer daily precipitation for regional U.K. precipitation series (1931-2011) have been mostly negative, while Jones et al. (2013) identify spatially varying changes in the median summer maxima. Although for some regions, these events appear to be increasing, in general, summer rainfall events have declined in intensity. A recent study (Brown 2018) has found that these previously reported trends in U.K. daily rainfall extremes, however, may be due at least in part to natural variability. In particular, the North Atlantic Oscillation (NAO) explains much of the trend in winter extreme rainfall from 1958 to 2012 (with the residual trend after inclusion of NAO much reduced in magnitude and significance) and any apparent trend in summer extreme rainfall.

Evidence of human influence on changes in rainfall has been accumulating globally. For example, Min et al. (2011) showed that human-induced warming has contributed to observed increases in the intensity of heavy 
precipitation over large parts of Northern Hemisphere land areas. However, the attribution of rainfall trends to human influence on local and regional scales is not yet possible (Sarojini et al. 2016). For some specific extreme events, it is possible to show that anthropogenic climate change increased the risk of the event: for example, the autumn 2000 floods in England and Wales (Pall et al. 2011) and the 2014 southern England winter floods (Schaller et al. 2016). However, this is not true of many other flooding events, and it is only with time that we can detect any underlying trend.

An important measure, therefore, to inform adaptation planning is detection time-that is, when changes in flooding are expected to move outside of what has been experienced in the past due to natural climate variability. The question of when we may be able to detect the influence of climate change on U.K. rainfall is examined here. This is important from a planning perspective, providing a time scale for necessary climate change adaptation measures. Detection time is also useful for evaluating climate model projections, as the emergence of the climate change signal predicted by the model can be tested using observations. Fowler and Wilby (2010) examined U.K. daily precipitation change from thirteen $50-\mathrm{km}-$ resolution regional climate model simulations from the PRUDENCE ensemble and found changes in the winter 10 -yr return level emerge in the 2040s, while changes in summer extremes are highly uncertain. A similar study using the climateprediction.net global climate model ensemble gave similar results (Fowler et al. 2010).

In this paper, we examine how detection time varies for U.K. precipitation accumulated across a range of time and space scales, including down to 10-min and kilometer scales, using output from a very high-resolution (convection permitting) climate model, and investigate the consistency of modeled detection times, with observed changes from gauge data in a new, quality-controlled dataset of hourly rainfall for the United Kingdom. Convection-permitting models do not necessarily better represent daily precipitation, compared to coarserresolution regional climate models (Chan et al. 2013), but they are needed to provide reliable projections of subdaily rainfall and, hence, an estimate of when we may be able to detect change on these time scales.

\section{Data and methods}

\section{a. Climate model}

A very high-resolution $(1.5 \mathrm{~km})$ climate model spanning the southern United Kingdom (including most of England and Wales) is used here. This was the largest domain possible to allow completion of decadal-length simulations in a reasonable time and includes regions with different rainfall characteristics. In particular, it includes southern England, where there is a high proportion of convective events in summer; London, where the urban environment has a considerable influence on the local climate; and the mountainous region of Wales, where there is orographic enhancement of rainfall. The model is a modified version of the nonhydrostatic Met Office operational U.K. variable-resolution model (UKV), a configuration of the Met Office Unified Model (UM), and is described in Kendon et al. (2014). For weather forecasting purposes, $1.5-\mathrm{km}$ grid spacing is the finest affordable resolution at which most convection over the United Kingdom is satisfactorily represented on the grid without the need for a convection scheme (Lean et al. 2008). Thus, in this model, the convection parameterization scheme is switched off. Thirteen-year present (1996-2009) and future climate ( 2100, RCP8.5 scenario) $1.5-\mathrm{km}$ simulations are driven by a $12-\mathrm{km}$ regional climate model, which spans Europe and is, in turn, driven by a $60-\mathrm{km}$ atmosphere-only general circulation model (GCM). The $12-\mathrm{km}$ RCM and $60-\mathrm{km}$ GCM both have the UM Global Atmosphere 3.0 configuration (Walters et al. 2011). Ten-minute precipitation has been output for the summer months (June-August) only due to the large data volume. Chan et al. (2016b) identified an intensification of these 10-min extremes that is consistent with that found at hourly time scales, and here, we build on these results, examining whether increases in hourly and 10-min extremes are detectable before changes in daily rainfall extremes.

The $1.5-\mathrm{km}$ model is based on the Met Office operational U.K. weather forecast model, and extensive testing within numerical weather prediction (NWP) trials indicates that the model produces realistic convective showers and is able to forecast localized extreme events not captured at coarser resolutions (Lean et al. 2008). The $1.5-\mathrm{km}$ model has also been shown to realistically capture hourly rainfall in long climate simulations. In particular, Kendon et al. (2012) showed that the model gives a much better representation of the intensity-duration characteristics of hourly rainfall, as well as its spatial extent, compared to a coarserresolution climate model. Kendon et al. (2014) showed that the intensity of heavy hourly rainfall and its spatial pattern across the southern United Kingdom is well captured in the $1.5-\mathrm{km}$ model in both summer and winter, while Chan et al. (2014b) showed that the model is more realistic in representing hourly precipitation extremes, compared to a $12-\mathrm{km}$ climate model. These improvements in the representation of subdaily rainfall characteristics are also seen in CPMs for other regions (Kendon et al. 2017). There is still a tendency for heavy 
rainfall to be too intense in the $1.5-\mathrm{km}$ model, which is a common deficiency in convection-permitting models (Kendon et al. 2017) and likely to be a consequence of convection not being fully resolved at kilometer scales. The model has not been evaluated at subhourly time scales from a climatological perspective due to the lack of U.K. quality-controlled multiyear subhourly observations (Chan et al. 2016b). Focused field campaigns [e.g., the Dynamical and Microphysical Evolution of Convective storms (DYMECS) project] have shown the $1.5-\mathrm{km}$ NWP model does not adequately represent short-lived storm life cycles, but results vary with the type of convective storms (Stein et al. 2015). We note that 10 -min output corresponds to $12(50 \mathrm{~s})$ model time steps, and so is approaching the limit imposed by discretization.

Following Fowler and Wilby (2010), we define a detectable increase in a given precipitation metric $D_{x}$ as the year at which we would reject (at the $\alpha=0.05$ or 95\% significance level) the null hypothesis that the metric for year $x\left(\mu_{x}\right)$ and the control period $\left(1996-2009, \mu_{c}\right)$ are equal, in favor of the alternative hypothesis that $\mu_{x}$ is not equal to $\mu_{c}$. Using a two-tailed test (with critical $Z$ score of 1.96), this corresponds to

$$
\left|D_{x}\right|=\frac{\left|\mu_{x}-\mu_{c}\right|}{\sqrt{\sigma_{f}^{2}+\sigma_{c}^{2}}} \geq 1.96,
$$

where $\sigma_{c}^{2}\left(\sigma_{f}^{2}\right)$ is the variance in the metric for the control (future) period. Assuming a linear trend in the metric through time between the present climate simulation (midyear 2003) and the future simulation (midyear 2103, metric $\mu_{f}$ ), we get the following for the earliest detection year $Y_{D}$ :

$$
Y_{D}=2003+196 \frac{\sqrt{\sigma_{f}^{2}+\sigma_{c}^{2}}}{\left|\mu_{f}-\mu_{c}\right|} .
$$

We have used bootstrap resampling to get an estimate of the variance of the metric, due to natural climate variability, in the control and future periods. For each season, we have randomly selected 13 years out of the 13-yr period, with replacement, such that in the resampled time series some years occur more than once and other years not at all. By this method, we are retaining any time correlations on subseasonal time scales and only assume independence between a given season for one year and the next. This resampling is done identically at each grid point, thus retaining any spatial coherence. The bootstrap resampling procedure is repeated 100 times, for each of the control and future periods. The precipitation metric of interest $\mu$ is then calculated at each grid point for each of the bootstrap samples. This allows the detection year $Y_{D}$ to be calculated at each grid point, using the variance across the 100 estimates of $\mu$ for the control and future periods. We finally calculate the median of all the detection times across southern U.K. land points to give a single central estimate, as well as the 10th and 90th percentiles of the spatial varying estimates to give an indication of uncertainty.

In this analysis, since we are restricted to single 13-yr simulations of the present and future climate, it is not possible to examine initial condition uncertainty. The method of resampling only accounts for year-to-year natural variability, with no consideration of multidecadal climate variability. The presence of significant multidecadal variability in the metric could lead to the actual detection time of the climate change signal being earlier or later than that estimated above, depending on where the control and future periods fall within this multidecadal cycle. We note, however, that given the way the future sea surface temperatures (SSTs) are configured in the driving GCM, we would expect this effect to be small. In particular, the future SSTs are configured as a time-invariant delta (given by the multiyear mean SST change for each month between 19902010 and 2090-2110 in HadGEM2-ES) applied onto the present-day time-varying SSTs [as described in Kendon et al. (2014)], and human-induced warming (of about $4 \mathrm{~K}$ globally) is expected to dwarf any influence of natural climate variability in the 20 -yr mean SST change. Another limitation of the approach here is that it assumes a linear trend in the metric between the control and future periods. In reality, it is likely that changes will start more slowly and then accelerate toward the end of the century, following the projected profile of human-induced warming. This will mean actual detection times are likely to be later than estimated, assuming a simple linear trend. Fowler and Wilby (2010) attempted to model this effect by applying a pattern scaling approach, assuming regional changes in precipitation will occur in proportion to the projected change in global mean temperature. In this paper, we just use the simple linear approach, but note this will not impact the finding of whether changes in daily or short-duration precipitation emerge first.

Here, we consider three precipitation metrics: (i) mean wet day/hour intensity (wet value is $>0.1 \mathrm{~mm}$ per accumulation period); (ii) heavy precipitation intensity, defined as the mean of the upper $5 \%$ of wet values $\left(p_{95}\right)$; and (iii) heavy precipitation, defined as the mean of the upper $1 \%$ of all values $\left(p_{99 \mathrm{ALL}}\right)$. The precipitation metrics are calculated for 10-min, hourly, and daily precipitation accumulations using the 13 years of data from the control and future simulations, respectively. 
They are also calculated for the $1.5-\mathrm{km}$ precipitation regridded to a range of coarser spatial scales $(5,12$, and $50 \mathrm{~km})$ using area-weighted averaging. All temporal and spatial averaging is carried out on the raw precipitation time series data before calculation of the metrics.

\section{b. Change detection in observations}

To examine whether evidence from historical observations are consistent with the detection times derived from the model projections, we use a new dataset of hourly precipitation for the United Kingdom. It should be noted that this observational analysis uses data across the whole of the United Kingdom, whereas the model data correspond only to the southern United Kingdom. However, we repeated the analysis with only those gauges within the model domain (Fig. 1) and found this did not give any qualitative difference in the results. The provenance and extensive quality control of the observational dataset, which comprises $\sim 1900$ rain gauges, are described in Blenkinsop et al. (2017). They indicate that although the earliest records commence in 1949, most of these gauges were installed in the 1990s, and so the number for which sufficiently long records exist for trend analysis is limited. The data have been updated for this study to the end of 2014 with additional qualitycontrol procedures, including comparison with neighboring gauges and validation against a high-quality gridded daily dataset (E. Lewis et al. 2018, manuscript submitted to J. Hydrol.). We also compared annual time series of mean 1- and 24-h intensities for all gauges within $25 \mathrm{~km}$ of each other by computing the Spearman rank $(S)$ correlation coefficient. Such an approach ideally requires a known, reliable reference gauge to identify potential errors, but in this instance, most gauges correlated highly with at least one other gauge. However, one gauge (Milcote, central England) was excluded from the analysis on the basis of low correlations $(S<0.26$ to 0.4$)$ with three neighboring gauges.

In addition, Blenkinsop et al. (2017) only analyzed the climatology of records of $\sim 20$-yr length and so did not consider potential inhomogeneities that may confound any analysis of change. We therefore applied a selection of statistical tests to identify breaks in the time series that may indicate inhomogeneities in the data and, in this case, enabled the identification of changes in the measurement resolution of many gauges. The full details of this procedure are provided in the supplemental information.

For the observational analysis, we carry out several approaches to assess the change in comparison with the model projection: (i) We calculate the same three precipitation metrics as for the analysis of the model simulations for the last 13-yr period of record (2002-14) and calculate the change in each statistic relative to earlier running 13-yr periods from the start of the record up to the period 1989-2001, hereinafter referred to as "percentage change."

(ii) For selected 13-yr periods, the changes in each metric are then normalized by the variability in the metric using the same resampling procedure as for the model analysis, resampling years in the $13-\mathrm{yr}$ start and end periods to produce the statistic $D_{x}$. This allows a direct comparison between the observational and model analyses. We refer to this approach as "normalized change."

(iii) In addition to calculating changes in the 13-yr statistics, we also calculate trends in yearly mean intensity and $p_{95}$ values. This approach provides a less robust measure of $p_{95}$ (since this equates to averaging only 5 -hourly values in a single season, assuming $5 \%$ of hours are wet, and less in the case of daily data) but allows all the observational data throughout the period of interest to contribute to the trend estimate and is an approach more typically used for the analysis of changes in a continuous time series. Trends are calculated using two methods: the longest available period at each gauge (minimum 30 years) and also using running 30-yr trends calculated from 1950 at 5-yr intervals (hereinafter referred to as "long" and "running" trends, respectively). The use of running trends allows an assessment of the sensitivity of any identified trends to the period of the record. Running trend analysis is a useful descriptive tool for climatic time series (Trottini et al. 2015) and has been used in a range of climate analyses, including attribution studies (e.g., Santer et al. 2014; Hamlington et al. 2013) and model evaluation (Risbey et al. 2014).

For the analysis of trends, significant monotonic trends were identified using the Mann-Kendall test (two tailed, 95\% significance level). Trend magnitudes were estimated using the nonparametric Sen's slope (Theil-Sen estimator). The Theil-Sen estimator of a set of twodimensional points $\left(x_{i}, y_{i}\right)$ is the median of the slopes $\left(y_{j}-y_{i}\right) /\left(x_{j}-x_{i}\right)$ determined by all pairs of sample points (Theil 1950a,b,c) and was extended (Sen 1968) for cases where two data points have the same $x$ coordinate (in this instance, time is the $x$ variable). To derive trends that are comparable across accumulation periods, we also calculated Sen's relative slope, the slope joining each pair of observations being divided by the first of the pair before the overall median is taken (Jassby and 
a)

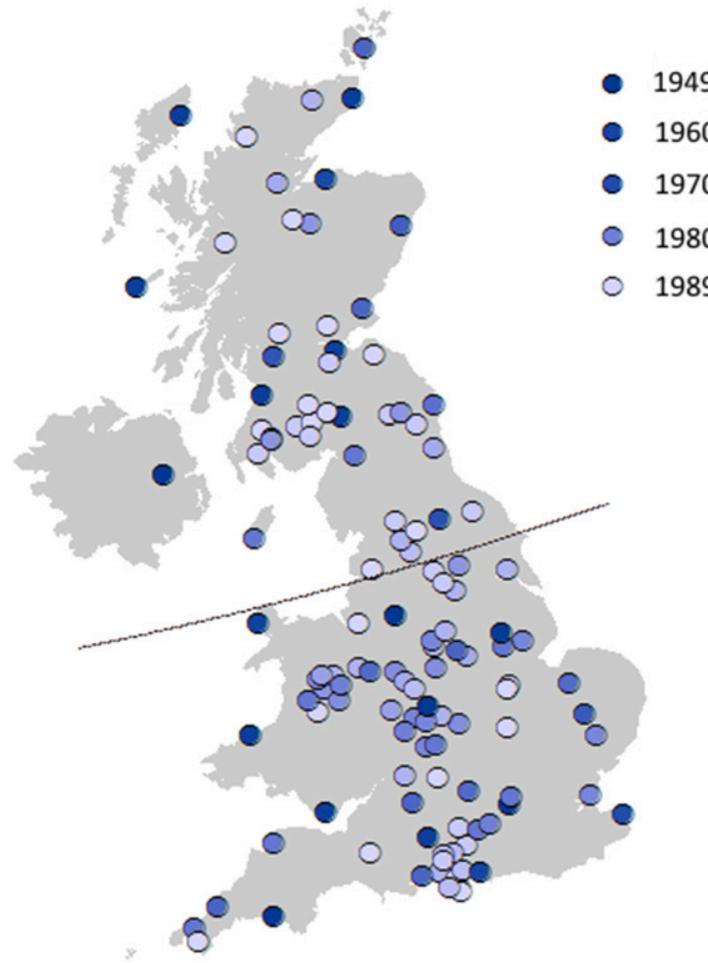

b)

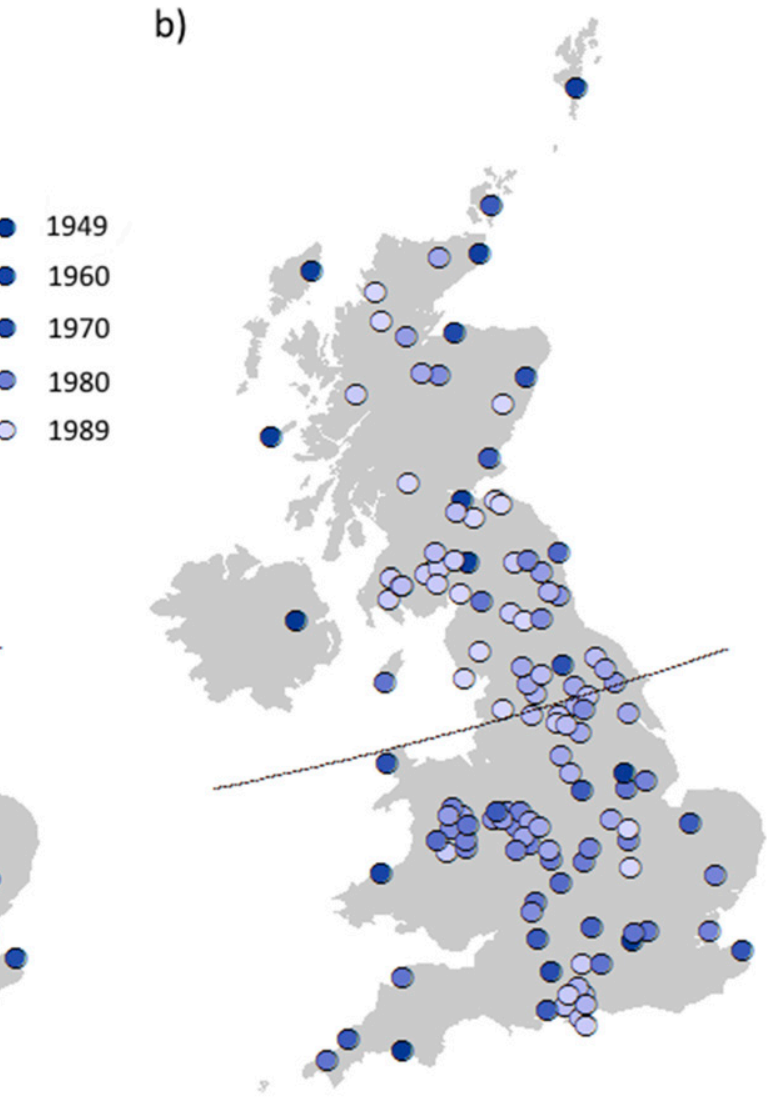

FIG. 1. Subdaily rain gauges included in the analyses for (a) DJF (123 gauges) and (b) JJA (130 gauges). Years denote the first year in the earliest 13-yr analysis period meeting the required level of completeness. Line denotes northern limit of the CPM simulation domain.

Cloern 2016), providing a normalized trend that allows comparison of series of different magnitudes and even units. For each period, estimated trend magnitudes for 1- and 24-h accumulations were also compared using a two-tailed Wilcoxon rank-sum test to test for significant differences in the trend means.

Gauges were selected for this analysis of change on the basis of their completeness. For assessments of the change in the 13-yr statistics, gauges were only included if they were at least $85 \%$ complete over the period 2002-14 and at least one other 13-yr period. For the trend analysis, we selected those gauges spanning at least 30 years [applying the same criteria as in Blenkinsop et al. (2017), where each year/season is at least $85 \%$ complete, and a minimum of $\sim 85 \%$ of years/seasons must also meet this criteria for use]. Further, gauges meeting these criteria were only included if missing periods did not occur at the beginning and/or end of a period used for trend estimation (i.e., data present truly reflect the period for which trends are estimated). In total, 123 (130) gauges are used in this analysis for DJF (JJA) (Fig. 1), but due to missing data, the number available at different periods and for different seasons varies, and fewer gauges were available for trend analysis due to the requirement for longer, continuous time series (Table 1). Subhourly gauge data from the Met Office (provided at a temporal resolution of $1 \mathrm{~min}$ ) and tipping-bucket rain gauge data from the U.K. Environment Agency were also examined, but these data did not meet the record length criteria, and so observed change in rainfall on 10-min time scales could not be assessed.

\section{c. Modes of variability}

To assess the influence of natural variability on observed trends, we examine changes in the NAO and the Atlantic multidecadal oscillation (AMO) using the Climatic Research Unit (CRU) NAO index (freely available at https://crudata.uea.ac.uk/cru/data/nao/; Jones et al. 1997) and the detrended AMO index (Enfield et al. 2001) available from NOAA (freely available at https:// www.esrl.noaa.gov/psd/data/timeseries/AMO/).

The NAO has long been considered the most important single mode for interpreting climate variability in the Northern Hemisphere (Walker 1924; Hurrell 1996), including winter precipitation in Europe (Hurrell 1995; 
TABLE 1. Number of gauges available for each season and for each method used for the analysis of change. The total number of unique gauges is also shown.

\begin{tabular}{lrr}
\hline \multicolumn{1}{c}{ Period } & DJF & JJA \\
\hline Percentage/normalized change & 108 & 115 \\
Long trends & 63 & 72 \\
Running trends & 73 & 78 \\
Combined unique & 123 & 130 \\
\hline
\end{tabular}

Hurrell and van Loon 1997; Trigo et al. 2002; Hoy et al. 2014), and has been noted to account for many of the observed changes in U.K. winter precipitation totals and daily extremes (Simpson and Jones 2014; Wilby et al. 1997; Brown 2018). Regional variations in the association between NAO and winter rainfall have been noted by Wilby et al. (2002).

Summer atmospheric circulation associated with the NAO, identified by Hurrell et al. (2003), has been noted to have a smaller spatial extent than in winter and was located farther north. However, the summer NAO (SNAO) has been shown to have the strongest influence on climate over northwestern Europe (Linderholm et al. 2009; Hoy et al. 2014). Osborn et al. (2000) showed that $\sim 60 \%$ of the variance in annual summer precipitation for regional series for central, eastern, and southern England rainfall can be explained by atmospheric circulation; Folland et al. (2009) identified that the summer (JA) SNAO explains the principal variations of summer climate over northern Europe, including mean precipitation with very strong and significant negative correlations of the SNAO index with summer rainfall, exceeding -0.64 over parts of the British Isles. However, Hoy et al. (2014) suggest that summer relationships are sensitive to the definition of the SNAO. Simpson and Jones (2014) did note some significant negative correlations between daily U.K. summer extreme rainfall and the SNAO, and consistent with this, Brown (2018) finds that positive SNAO reduces the likelihood of extreme daily rainfall in summer, accounting for much of the variability from 1958 to 2012. In contrast, Wilby et al. (2002) identify positive correlations between the SNAO and mean summer wet day amount for a cluster of sites across northern Wales and England. This spatially varying response of the negative phase of the SNAO is also noted by Hoy et al. (2014).

The AMO has been noted to be linked to changes in the summer NAO (Folland et al. 2009): several studies suggest that 1990s Atlantic warming was a consequence of an acceleration of the Atlantic meridional overturning circulation (AMOC) linked with the positive phase of the winter NAO in the 1980s and 1990s (Robson et al. 2012; Lohmann et al. 2009). The AMO has been identified as an indicator of the importance of the Atlantic Ocean in influencing
European climate, including recent wet summers in northern Europe (Sutton and Dong 2012). Sutton and Dong (2012) indicated that coherent and consistent patterns of precipitation anomalies suggested changes in atmospheric circulation associated with a warm state of the North Atlantic. We note, however, that Brown (2018) finds no influence of the AMO (as an additional covariate to the NAO) for U.K. daily extremes.

In the analysis here, seasonal $\mathrm{NAO}$ and $\mathrm{AMO}$ indices are calculated as the mean index value over the corresponding 3 months, along with 15-yr moving averages for comparison with the trends in $p_{95}$ observations.

\section{Results}

\section{a. Model detection times}

The CPM simulation suggests that detectable changes in 13-yr mean precipitation intensity in winter may emerge across the southern United Kingdom in the 2040s (Table 2), which is in good agreement with the results of Fowler and Wilby (2010). Detection times are consistently earlier for hourly compared to daily precipitation, with differences of about 5-10 years in the median detection year across the southern United Kingdom. Detection times are also generally earlier for precipitation averaged over larger spatial scales. A similar variation in detection time is seen for changes in heavy precipitation intensity $\left(p_{95}\right)$ in winter (Table 2$)$. Changes in the top $1 \%$ of all values ( $\left.p_{\text {99ALL }}\right)$ emerge later than changes in wet-value statistics (both mean precipitation intensity and $p_{95}$ ), with $p_{99 \mathrm{ALL}}$ reflecting changes in both the intensity and frequency of events. The 10th and 90th percentiles of the spatially varying estimates of detection year (in parentheses in Table 2) typically span about $40-50$ years, with changes in hourly precipitation emerging in the 2030s for some local regions. Maps showing the spatial variability in detection time (Fig. 2) indicate that changes in heavy precipitation may be detected earlier toward the north and west in winter, perhaps suggestive of more westerly U.K. winters with climate change (Malby et al. 2007).

Changes in precipitation emerge later in summer, compared to winter (Table 3). For daily precipitation intensity in summer, detectable changes have not even emerged by the end of the century. However, hourly and 10-min precipitation changes emerge earlier by many decades. For heavy 10-min precipitation intensity, results suggest detectable changes may typically emerge across the southern United Kingdom in the 2080s. Changes in the top $1 \%$ of all values $\left(p_{99 \mathrm{ALL}}\right)$ emerge considerably later than changes in wet-value statistics (both mean precipitation intensity and $p_{95}$ ) due to large 
TABLE 2. Median detection year across southern U.K. land points for changes in (top) precipitation intensity, (middle) heavy precipitation intensity $p_{95}$, and (bottom) heavy precipitation $p_{99 \mathrm{ALL}}$ in winter for precipitation accumulated across a range of space $(1.5-50 \mathrm{~km})$ and time (hourly-daily) scales. Also shown in parentheses are the 10th and 90th percentiles of the spatially varying estimates of detection year. Precipitation intensity is defined as the mean of wet values $(>0.1 \mathrm{~mm}$ per accumulation period) over the 13 -yr period, heavy precipitation intensity is defined as the mean of the upper $5 \%$ of wet values $\left(p_{95}\right)$, and heavy precipitation is defined as the mean of the upper $1 \%$ of all values $\left(p_{99 \mathrm{ALL}}\right)$.

\begin{tabular}{|c|c|c|c|c|}
\hline & $1.5 \mathrm{~km}$ & $5 \mathrm{~km}$ & $12 \mathrm{~km}$ & $50 \mathrm{~km}$ \\
\hline \multicolumn{5}{|c|}{ Precipitation intensity } \\
\hline Daily & $2050(2033,2086)$ & $2051(2033,2090)$ & $2051(2034,2092)$ & $2050(2033,2100)$ \\
\hline Hourly & $2048(2034,2071)$ & $2046(2034,2073)$ & $2045(2034,2075)$ & $2041(2032,2060)$ \\
\hline \multicolumn{5}{|c|}{ Heavy precipitation intensity $p_{95}$} \\
\hline Daily & $2056(2042,2084)$ & $2056(2042,2085)$ & $2055(2041,2084)$ & $2054(2040,2077)$ \\
\hline Hourly & $2051(2032,2073)$ & $2050(2032,2072)$ & $2048(2032,2069)$ & $2042(2032,2061)$ \\
\hline \multicolumn{5}{|c|}{ Heavy precipitation $p_{99 \mathrm{ALL}}$} \\
\hline Daily & $2071(2048,2117)$ & $2070(2048,2115)$ & $2069(2048,2112)$ & $2061(2044,2098)$ \\
\hline Hourly & $2055(2033,2084)$ & $2055(2033,2082)$ & $2053(2034,2078)$ & $2050(2034,2071)$ \\
\hline
\end{tabular}

decreases in the frequency of rainfall in summer (Chan et al. 2014a) at least partially offsetting increases in rainfall intensity for all-value statistics. There is considerable spatial variability in the detection time in summer, with the 10th and 90th percentiles of the spatial estimates (in parentheses in Table 3) spanning a century or more. Maps of detection time (Fig. 2) indicate there is a less clear spatial pattern in detection time in summer, compared to winter. Thus, in summer, there is considerable uncertainty in detection time; there may be some local regions where changes in short-duration heavy summertime precipitation emerge as early as the 2050s but others where there is no detectable change well beyond the end of this century.

We note that here, a constant threshold of $0.1 \mathrm{~mm}$ has been applied to define a wet value across all accumulation periods and spatial scales. It is easier to reach a $0.1-\mathrm{mm}$ accumulation over a day than over a 10 -min period. In particular, since rain typically lasts longer than $10 \mathrm{~min}$ (and, in winter, longer than an hour), the daily accumulation on days with 10 -min periods exceeding $0.1 \mathrm{~mm}$ will likely be considerably higher than $0.1 \mathrm{~mm}$, while days just exceeding the $0.1-\mathrm{mm}$ threshold may likely contain no individual hours or 10-min periods selected as wet. (Note this is only the case for the model results; for the observations where there is a minimum tip ranging from 0.1 to $0.5 \mathrm{~mm}$ depending on gauge, detailed in the supplemental information, if a day reports $0.1 \mathrm{~mm}$, then there must be an hour with $0.1 \mathrm{~mm}$.) This then raises the question of whether the finding that $10-\mathrm{min}$ precipitation changes emerge earlier is simply because we are preferentially selecting the higher-intensity events at shorter accumulation periods (although there will still be considerably more 10 -min wet periods than
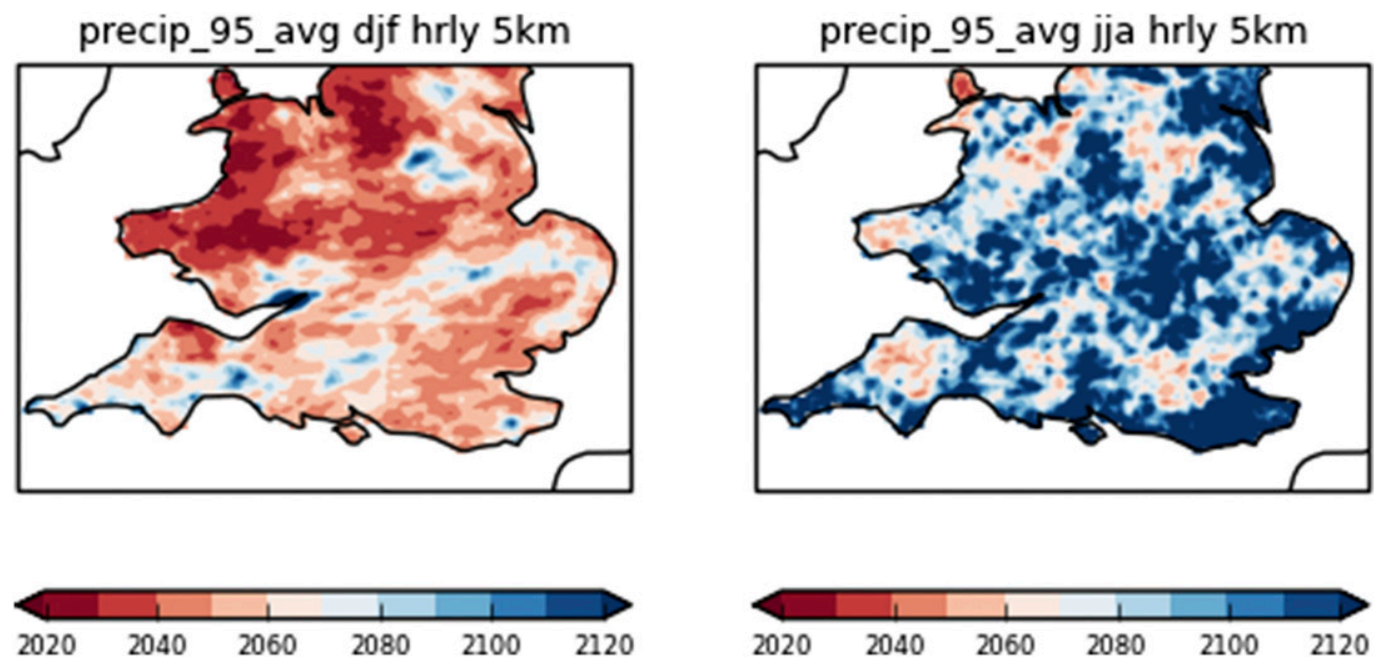

FIG. 2. Spatial variation in detection year across the southern United Kingdom for changes in heavy precipitation intensity $p_{95}$ in (left) winter and (right) summer for hourly precipitation at 5 -km scale. Heavy precipitation intensity is defined as the mean of the upper $5 \%$ of wet values $\left(p_{95}\right)$. 
TABLE 3. As in Table 2, but for changes in (top) precipitation intensity, (middle) heavy precipitation intensity $p_{95}$, and (bottom) heavy precipitation $p_{99 \mathrm{ALL}}$ in summer. In this season, results are also available for 10-min precipitation.

\begin{tabular}{|c|c|c|c|c|}
\hline & $1.5 \mathrm{~km}$ & $5 \mathrm{~km}$ & $12 \mathrm{~km}$ & $50 \mathrm{~km}$ \\
\hline \multicolumn{5}{|c|}{ Precipitation intensity } \\
\hline Daily & $2252(2117,3211)$ & $2261(2119,3247)$ & $2261(2124,3426)$ & $2325(2129,4195)$ \\
\hline Hourly & $2123(2078,2299)$ & $2121(2076,2315)$ & $2116(2072,2289)$ & $2121(2079,2314)$ \\
\hline $10 \mathrm{~min}$ & $2107(2072,2198)$ & $2100(2068,2186)$ & $2093(2062,2171)$ & $2114(2069,2187)$ \\
\hline \multicolumn{5}{|c|}{ Heavy precipitation intensity $p_{95}$} \\
\hline Daily & $2178(2095,2814)$ & $2186(2099,2858)$ & $2210(2107,3027)$ & $2266(2138,2874)$ \\
\hline Hourly & $2097(2064,2182)$ & $2095(2062,2179)$ & $2096(2062,2188)$ & $2126(2085,2257)$ \\
\hline $10 \mathrm{~min}$ & $2088(2059,2157)$ & $2083(2054,2146)$ & $2091(2056,2179)$ & $2184(2084,2543)$ \\
\hline \multicolumn{5}{|c|}{ Heavy precipitation $p_{99 \mathrm{ALL}}$} \\
\hline Daily & $2308(2126,3625)$ & $2320(2128,3617)$ & $2314(2131,3514)$ & $2329(2127,3006)$ \\
\hline Hourly & $2175(2092,2744)$ & $2188(2097,2821)$ & $2205(2105,2974)$ & $2211(2124,5058)$ \\
\hline $10 \mathrm{~min}$ & $2107(2069,2224)$ & $2119(2075,2273)$ & $2147(2088,2454)$ & $2211(2121,3572)$ \\
\hline
\end{tabular}

wet days in the 13-yr simulation). Looking at detection times for changes in all-value statistics $\left(p_{99 \mathrm{ALL}}\right)$, however, shows this is not the case, with short-duration extremes consistently emerging earlier than daily extremes even when no wet-value threshold is applied. Also, comparing detection times for precipitation intensity with those for heavy precipitation intensity $\left(p_{95}\right)$ shows that detection times are not always earlier for higherintensity events (Tables 2 and 3). Thus, we argue it is the impact of increasing atmospheric moisture with warming, which tends to result in rainfall falling as fewer but more intense events, that gives greater increases in intensity at shorter accumulation periods and, hence, favors the earlier detection of changes in 10-min and hourly precipitation. For the analysis of observations in the following section, we focus on changes in heavy precipitation intensity $\left(p_{95}\right)$, since these emerge earlier than all-day (and all hour) extremes in the model. This is consistent with large decreases in rainfall occurrence (particularly in summer due to changing circulation patterns; Chan et al. 2014a) offsetting increases in rainfall intensity due to increasing atmospheric moisture. We note, however, that the detection time for allday and all-hour extremes is important, as this directly relates to when changes in flooding frequency will be detected (see section 4).

Given these results are from single 13-yr model realizations of the present and future climate, assume a linear trend through time, and do not account for multidecadal natural variability (see section 2 ), we have low confidence in the actual detection years quoted. In particular, where detection times are beyond the end of the century, this reflects an extrapolation of the linear trend beyond the future simulation period; hence, we have very low confidence in these values, especially given the projected profile of human-induced warming is far from linear over long periods. However, the finding that changes consistently emerge earlier for 10 -min precipitation, compared to hourly and in turn daily precipitation, is expected to be more reliable. As noted above, it is consistent with the expected intensification of precipitation with climate change (Trenberth et al. 2003), such that changes in precipitation intensities are expected to be larger for shorter accumulation periods. This has been shown to be the case in summer in results from CPMs over both the United Kingdom and the Alps (Kendon et al. 2017). Results here suggest this greater signal of change dominates over any increases in noise associated with relatively greater natural variability at short time scales, at least where there is perfect sampling across space and time (but note, as discussed later, sampling issues in observational datasets may impact this). We note variance estimates for the model control simulation agree well with observed variance for the 2002-14 period, for both hourly and daily precipitation (Supplemental Tables S1 and S2), which gives credibility to the noise estimation that goes into the calculation of model detection time. Variance estimates for the future simulation are larger (by a factor of 2-3 for hourly precipitation), consistent with increased heavy precipitation intensity.

\section{b. Results from observed change analysis}

To examine results derived using the percentage change method, we calculate the median of the percentage changes across all contributing gauges to give a single central estimate across the United Kingdom, as well as the 10th and 90th percentiles of the spatially varying estimates to give an indication of uncertainty. Analysis of the results for $p_{95}$ indicates significant spread in the magnitude of change across the gauges along with variation in the magnitude, according to the periods used (Fig. 3). For winter, most gauges indicate a decrease for the 2002-14 period relative to preceding periods from those centered around 1980 onward. In contrast, for summer, positive changes clearly emerge over the same periods, particularly for 24 -h accumulations. We 

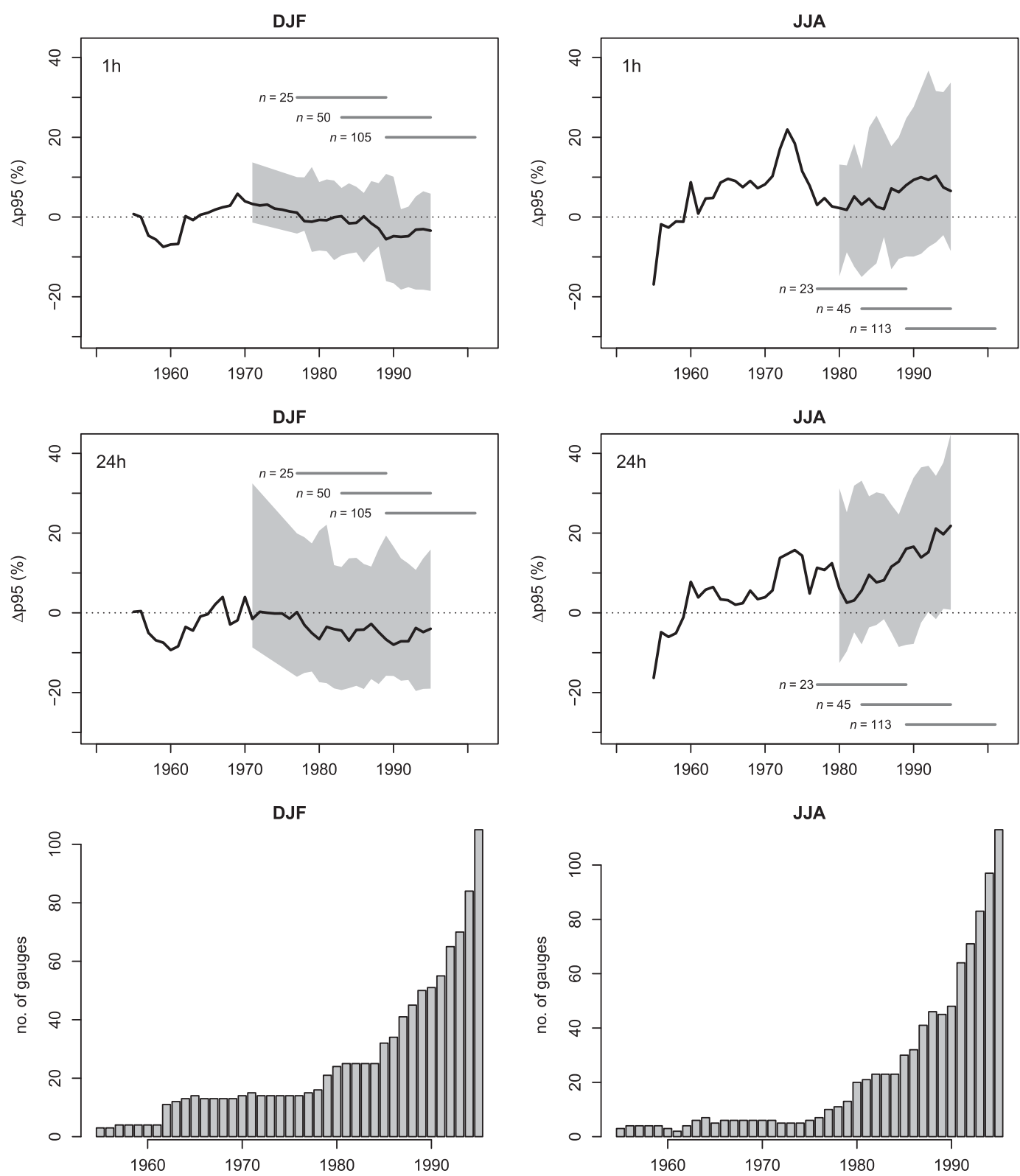

FIG. 3. Percentage change in heavy rainfall intensity $\left(\Delta p_{95}\right)$ for the period 2002-14 relative to successive rolling 13-yr periods in the observations (top row: $1 \mathrm{~h}$; middle row: $24 \mathrm{~h}$ ). Change is plotted at the midpoint of the earlier 13 -yr period. The solid line denotes the median of the change across all available gauges, and the shading denotes the range bounded by the 10th- and 90th-percentile ranges where at least 15 gauges are available. The horizontal lines indicate the periods used to resample the observed time series to evaluate normalized change. The bar plots (bottom row) denote the number of gauges available for each period.

note, though, that changes relative to earlier periods, particularly for summer, are characterized by low gauge availability, and so results are less robust. Similar patterns of changes are observed in the mean intensity (Fig. S2), but with slightly smaller magnitude of change for summer over recent decades.

We then applied the normalized change method for three $13-\mathrm{yr}$ periods to more directly compare the observed changes with those from the model. The variability of each metric (obtained by resampling years in the 13-yr start and end periods; see section 2b) was used to calculate the statistic $D_{x}$, where here, the metric $\mu_{x}$ refers to the latest 13-yr period in the observations (i.e., the midpoint $x$ is 2008), and $\mu_{c}$ is the statistic for successive $13-y r$ periods. The periods $1977-89,1983-95$, and 1989-2001 were selected to avoid the earlier part of the 
record with minimal numbers of gauges. Figure 4 shows the distribution of values of $D_{x}$ for the heavy precipitation intensity metric $\left(p_{95}\right)$. By comparison, the median $D_{x}$ for the model for 100-yr changes (midyear 2103 vs 2003) in $p_{95}$ is 4.10 (2.08) for hourly precipitation at the $1.5-\mathrm{km}$ scale in DJF (JJA). Under the assumption that changes in $p_{95}$ are linear through time, this would give a $D_{x}$ value for the model for 25 -yr changes (midyear 2028 vs 2003) of $1.03(0.52)$ for hourly precipitation at the $1.5-\mathrm{km}$ scale in DJF (JJA). As shown in Fig. 4 , these model $D_{x}$ values are within the 10th- to 90th-percentile ranges shown for the observations for a 25 -yr change (midyear 1983 vs 2008). Observed changes in Fig. 4 are consistent with those for the percentage change in Fig. 3. Winter changes in $p_{95}$ are relatively modest and are similar for both 1 - and 24-h accumulations, with a tendency for the period 2002-14 to show a decrease relative to periods from the early 1980 s onward. Again, for summer, the period 2002-14 shows potentially larger increases emerging in daily accumulations, compared with hourly. The magnitude of the estimated change is sensitive to the periods used, but we reiterate that longer-term changes are limited by gauge availability and so may not be representative. Comparable analyses for mean intensities (Fig. S3) and for $p_{99 \mathrm{ALL}}$ (Fig. S4), along with those for $p_{95}$ using only those gauges in the model domain (Fig. S5), do not appear to present qualitatively different results, and so here we focus on the analysis of heavy precipitation intensity $p_{95}$ using pooled gauges for the whole United Kingdom to maximize the detectability of change.

We next examined the spatial pattern of the normalized change in $p_{95}$ to explore whether any regions might emerge as potential sentinels of a climate change signal. Fowler and Wilby (2010), for example, used RCM projections to suggest that southwest England could be one such region for 10-day winter precipitation totals with a $10-\mathrm{yr}$ return period. Here, the pattern of normalized change for hourly winter precipitation (relative to 19892001) is weak, with some evidence of decreases tending to occur in the east (Fig. S6a), whereas for summer the north and east of the United Kingdom show the strongest increases (Fig. S6b). This latter pattern is replicated when compared with the period $1977-89$, but only 23 gauges are available; it is also similar for daily precipitation, though with a reduced regional contrast (not shown). The lack of long-term gauges means it is not possible to make robust inferences on the spatial pattern of change, and so we do not consider this further in this analysis.

These results may be compared with those obtained using trends calculated using the maximum length of data available (long method), which shows that for gauges of $>40$ years' length, trends in mean winter rainfall intensity are largely positive (Fig. S7a) though are not statistically significant at either the daily or hourly time scale. These positive trends are characteristic of those detected using the U.K. daily rain gauge network (see section 1); however, in this analysis, over shorter, recent periods (calculated from 1980 onward), a larger number of gauges exhibit contrasting nonsignificant negative trends. Comparing the mean of the relative Sen's slopes for 1- and 24-h rainfall intensity (Fig. S7) shows no clear pattern of a difference in trends between the two time scales. This is confirmed by the absence of significant differences (95\% level) signified by the Wilcoxon rank-sum test. A similar pattern is seen for trends in winter $p_{95}$, with lower positive trends and more frequent negative trends over the most recent decades (Fig. 5a for relative trends and Figs. S8 and S9 for absolute trends). Using the 30-yr running trend analysis highlights even more clearly the (multi)decadal-scale variability and trend sensitivity to the period of analysis, showing a distinct shift from positive to negative trends from the period 1975-2004 and onward (Fig. 5b).

As noted previously, summer is characterized by a particularly low number of gauges until $\sim 1980$, and so trends over earlier periods may not be representative of changes across the whole of the United Kingdom; however, more gauges generally exhibit (nonsignificant) positive trends throughout (Fig. 6 for relative trends and Figs. S8-S11 for absolute trends). Another clear pattern that emerges is higher relative trends at both time scales from the 1980s onward (Fig. 6a), including the emergence of some trends that are statistically significant (Figs. S8, S9). This is consistent with the analysis using the normalized change approach and with previous work by Simpson and Jones (2014), who noted that a series of wet summers starting in 2007 were beginning to offset a longer-term downward trend in mean and extreme U.K. daily summer rainfall. During this later period, relative trends are also smaller for 1-h than 24-h accumulations, which is contrary to the CPM simulation and the observed scaling of hourly and daily rainfall with temperature (Chan et al. 2016a). Again, the 30-yr running trend analysis highlights trend variability, showing an increase in the mean intensity (Fig. S12) and in $p_{95}$ (Fig. $6 \mathrm{~b}$ for relative trends; Figs. S8 and S9 for absolute trends) trends for the 1985-2014 period.

We reiterate the need for caution, however, in the interpretation of the temporal variability in trends observed in these figures. Figures 3, 5, and 6 indicate the relatively small number of gauges for the early period. In particular, in summer, all gauges contributing records for periods from 1970 and earlier are in Scotland or Northern Ireland (Fig. 1) and so may only be indicative 

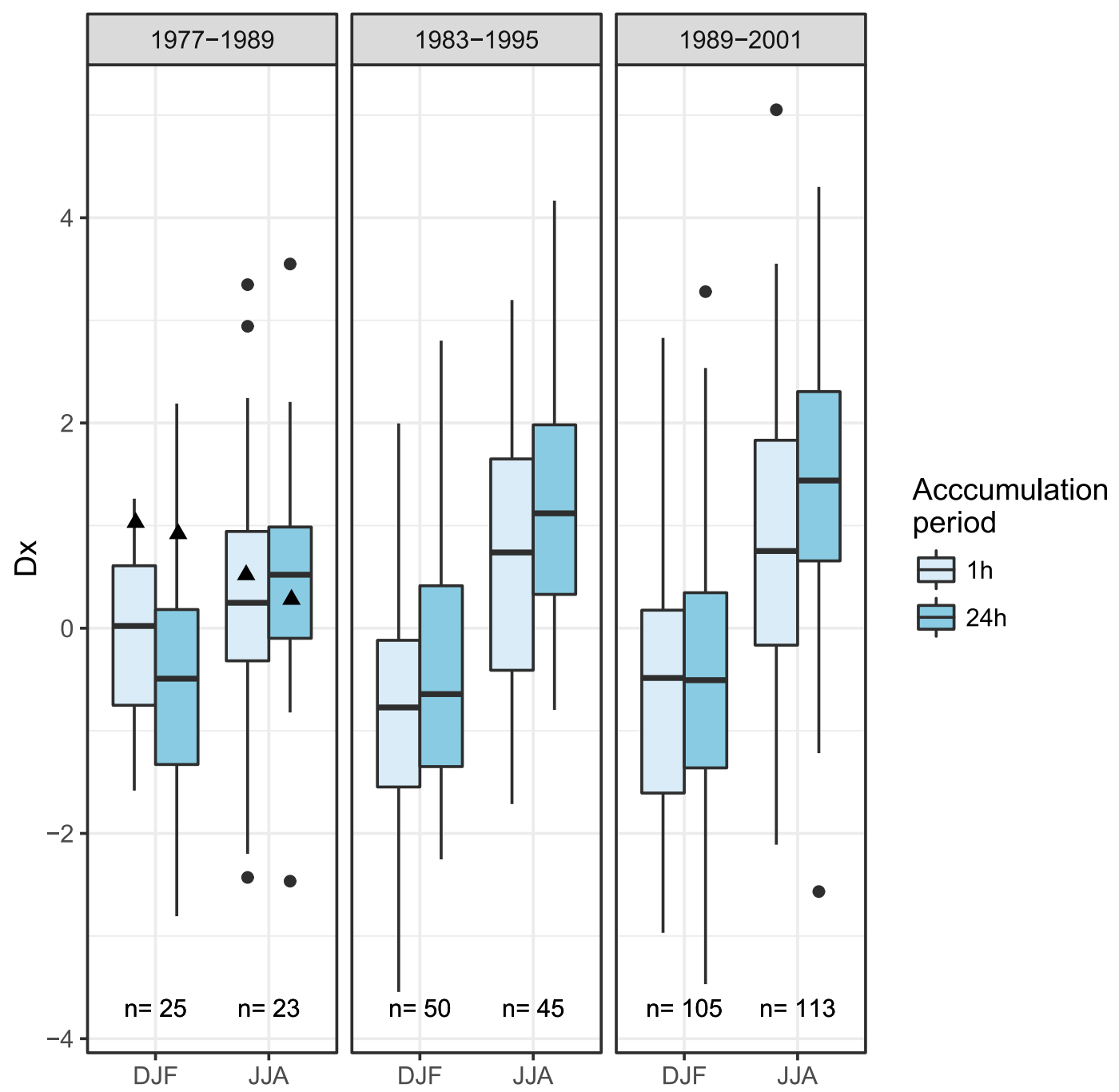

FIG. 4. Distribution of normalized change in heavy rainfall intensity $\left(p_{95}, D_{x}\right)$ for 1- and 24-h accumulations for the period 2002-14 relative to three 13-yr periods in the observations. The black triangles denote the median of the corresponding $1.5-\mathrm{km}$ model results for a 25 -yr change (scaled linearly from the 100 -yr change). The value $n$ denotes the number of gauges available for each period used to calculate change.

of regional change. Only from 1980 onward are there a significant number of gauges covering England and Wales. This problem is less pronounced in winter, for which the longer gauges are more evenly distributed across the United Kingdom, but with northern and eastern England less represented. To explore this further, we recalculated the long trends using just those gauges that provide data for all periods from 1955 onward for consistency; thus, trends for each period were based on identical gauges, albeit for a very small sample (DJF: 11; JJA: 5). Nonetheless, there is a degree of consistency with the complete sample of gauges. In winter, there is a clear decrease in the trend for 1-h heavy precipitation intensity (Fig. S13a) but with a less clear response of 24-h totals, which shows a lower sensitivity to the calculation period. Summer (JJA) is especially constrained by the limitations noted above, but there is a clear tendency for increasing trends (especially for $24 \mathrm{~h}$ ) over recent decades (Fig. S13b).

\section{c. Potential contributors to trend variability}

The sensitivity of observed trends to the period of calculation suggests potential influence of natural variability, and so here, we investigate two natural modes of variability: the NAO and the AMO.

Figure 7 a shows the previously documented positive phases of the winter NAO in the 1980s and 1990s and subsequent decrease in the index thereafter. The positive phase of the winter NAO is associated with wetter weather in northern Europe, and so trends calculated 

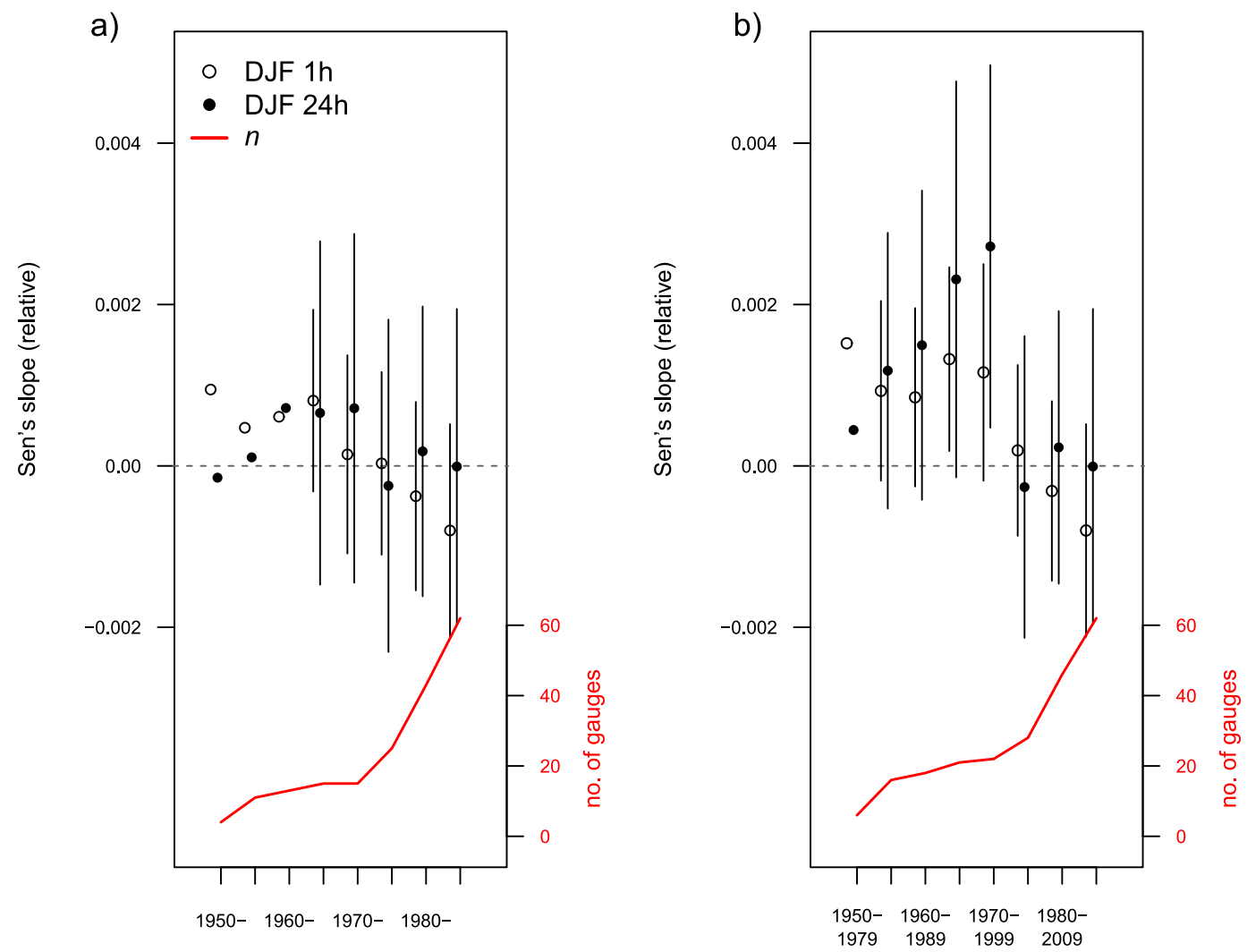

FIG. 5. Relative Sen's slope (unitless) for winter (DJF) hourly and daily heavy rainfall intensity $\left(p_{95}\right)$ in the observations for (a) successive periods ending in 2014 (long trends) and (b) successive 30-yr periods (running trends). Points show mean slope of all gauges while ranges show the $95 \%$ confidence interval estimated using the Student's $t$ distribution when the number of gauges $n>=15$ (see supplemental information for method details). Lower plots shows the number of gauges used for each period.

from this period are likely influenced by increased precipitation at the start of the record, potentially contributing to the lower or even decreasing trends shown in Figs. 4, 5, S8, and S9. Overlaying the mean running trends of $p_{95}$ shows consistency with the smoothed NAO time series, with a marked decrease in the period after the peak of the positive NAO phase.

The notable increase in recent summer trends also corresponds with a negative phase of the summer NAO (SNAO) (Fig. 7b). This is consistent with previous literature suggesting significant negative correlation of the SNAO with summer rainfall over parts of the United Kingdom (section 2c). Figure $7 \mathrm{c}$ also shows a strong increase in the summer AMO since the mid-1990s, again coincident with the increase in the magnitude of running trends and percentage change for summer $p_{95}$. The AMO has been noted to be linked to changes in the summer NAO, as well as recent wet summers over northern Europe (section 2c). Thus, overall, the observed trends in $p_{95}$ in summer appear to be strongly influenced by the NAO, which in turn may be related to the AMO. We also compared the teleconnection indices to variations in the ratio of the daily to hourly change in $p_{95}$, but noted that this was relatively stable and appeared unrelated to variability in the NAO and AMO. This suggests that these modes of variability may not readily explain any differences in change between the two accumulation periods, but further work might usefully investigate how natural variability affects the relative behavior of extremes of different durations.

\section{Discussion}

The results here suggest it is changes in precipitation intensity (or heavy precipitation intensity) that offer the greatest promise for detecting human influence on precipitation. Such changes are linked to increasing atmospheric moisture with warming and are expected to be robust across models. Changes in precipitation extremes measured using all values are found here to consistently emerge later due to these reflecting changes in intensity and frequency. However, it is these 

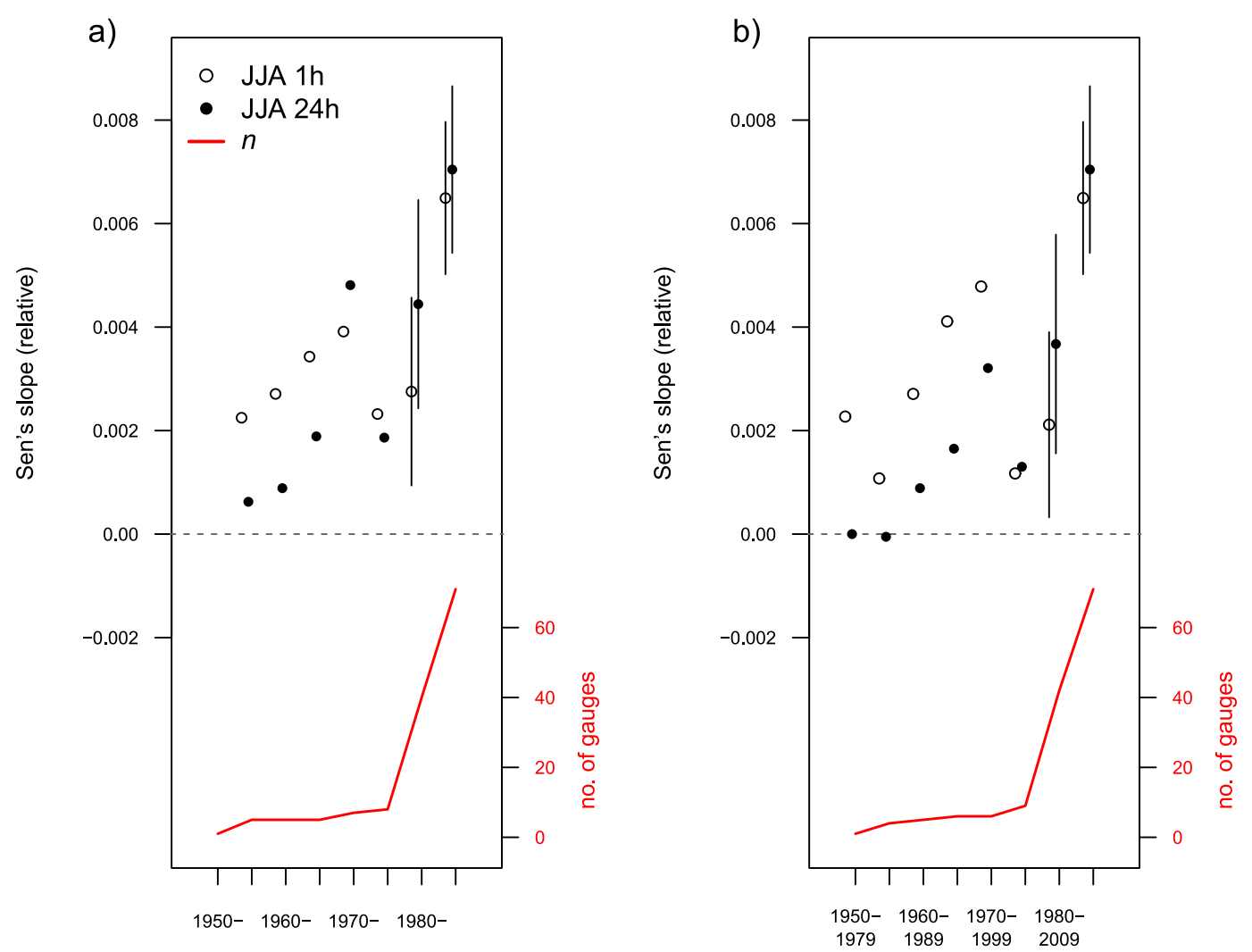

FIG. 6. As in Fig. 5, but for summer (JJA).

changes in intensity and frequency combined that will be felt in terms of flooding. Model results here suggest that changes in summertime urban flash flooding, which respond to changes in short-duration rainfall, may not be detected this century. Changes in fluvial flooding, which respond to changes in more persistent rainfall, may be detected earlier where these are dominated by changes in wintertime precipitation extremes [specifically for daily precipitation extremes: the CPM here suggests changes emerge in the 2060s for $p_{99 \mathrm{ALL}}$ for precipitation aggregated to the $50-\mathrm{km}$ scale, while Fowler and Wilby (2010) suggest the 2040s for the 10-yr return level].

It is important to note that the detection-time methodology has only been applied here to a single realization of future climate change from one climate model, and thus, no estimate of modeling uncertainty in the quoted detection times is possible. Also, it has not been possible to account for the influence of multidecadal natural variability from a single pair of $13-y r$ control and future simulations. Additional ensemble CPM experiments will allow an assessment of the robustness of these results. In particular, the next set of U.K. climate projections, to be delivered in 2018 (UKCP18), will include the first ensemble of CPM simulations over the United Kingdom. This will allow a much better assessment of the influence of natural climate variability, including multidecadal variability and, hence, a more robust evaluation of detection time. Furthermore, coordinated multimodel ensemble experiments at convection-permitting-scale are being carried out across Europe as part of a CORDEX Flagship Pilot Study (FPS).

The results here correspond to using 13 years of data to calculate the metric for the control and future periods. Using more years of data, once these become available, would make detection of the change easier. In particular, where a continuous time series of data is available up to 2050 and beyond (as will become available with time for observations and, for CPMs, is planned under ongoing research at the Met Office beyond UKCP18), the metric could be calculated for multiple (nonoverlapping) periods and then detection of the change undertaken using all the data. This is likely to result in earlier detection times than those quoted here.

The first major study of change in U.K. subdaily rainfall observations presented here provides some evidence of long-term increases in winter rainfall intensities, as projected by the models. In particular, these are evident in long trends for gauges with $>40$ years' 


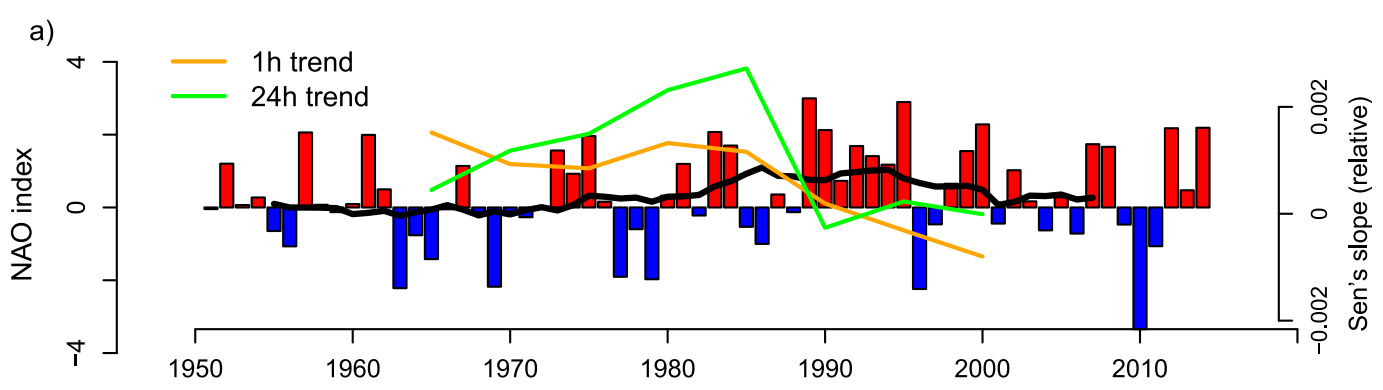

b)

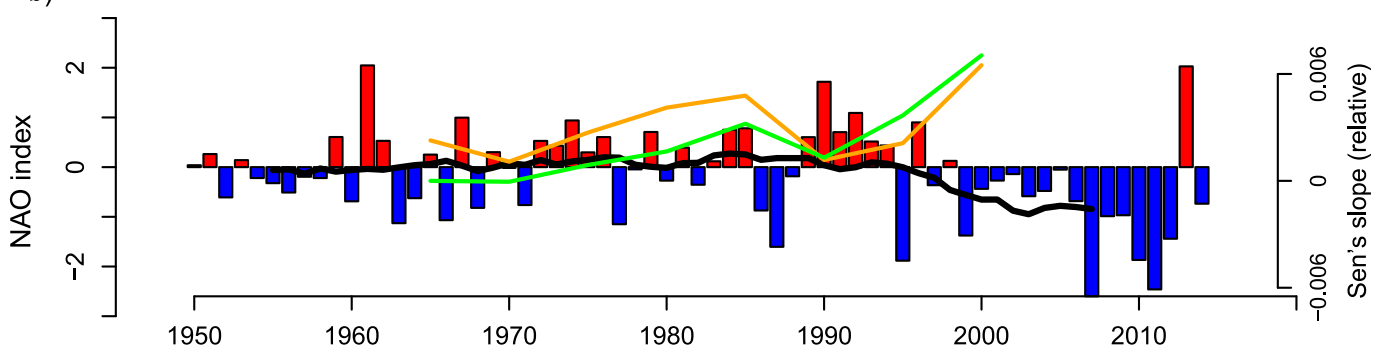

c)

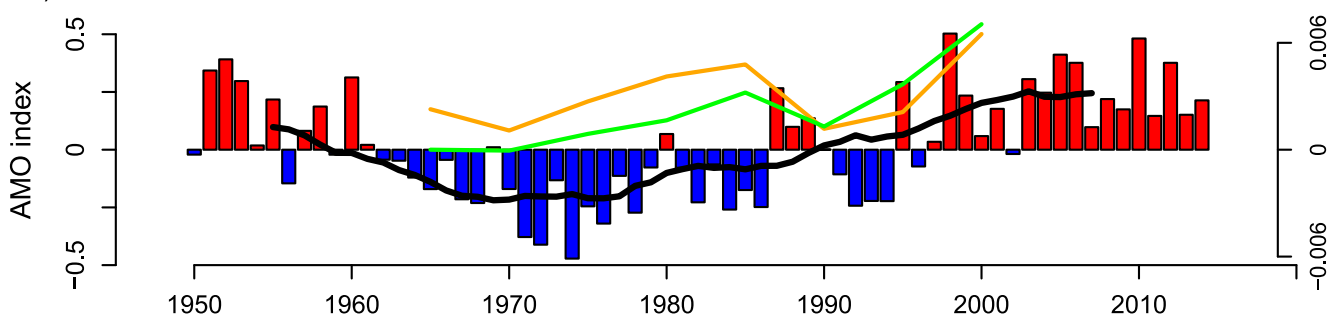

FIG. 7. Time series of teleconnection indices for (a) DJF NAO, (b) JJA NAO, and (c) JJA AMO. The black line denotes the 15-yr moving average. The orange and green lines indicate the mean seasonal relative Sen's slope for 1- and 24-h $p_{95}$ using running trends for each 30-yr period plotted at the midyear.

record and are seen in percentage changes between the periods of 2002-14 and pre-1980. However, these winter intensity increases are less consistent than extensive previous research on U.K. daily rainfall. These results are, however, constrained here by the low number of long-term subdaily gauges available for the analysis. The observations do also exhibit the emergence of recent increases in subdaily heavy rainfall intensities in summer. However, the earlier emergence of detectable changes in winter in the model is not seen in the observations, which may be explained by natural variability dominating observed trends at present. Also, in contrast with the CPM simulation, no consistent, significant difference between changes in 1- and 24-h rainfall is detected in either season. Barbero et al. (2017) similarly note an absence of the greater detectability of increases in hourly extremes, compared with daily, for U.S. annual and seasonal maxima, except during winter. We consider that this lack of a difference between daily and hourly trends, compared with the CPM simulations, could be due to a combination of the following:
- Relatively short records, particularly in summer, make trend detection more difficult due to a low signal-tonoise ratio.

- A relatively sparse network of rain gauges means that we are not able to adequately sample convective storms and their peak rainfall intensities on hourly time scales due to the limited spatial extent of events (Agel et al. 2015; Wasko et al. 2016). In contrast, winter extremes, albeit smaller in magnitude (Blenkinsop et al. 2017), are largely driven by midlatitude storms with large-scale synoptic forcing and are thus more consistent in space and better captured by the sparse gauge network.

- Barbero et al. (2017) also hypothesize that the measurement-interval truncation problem may also contribute to the lack of a trend in summer hourly extremes. Maximum hourly intensities over a day are likely to be truncated due to the fixed hourly intervals of precipitation measurement/recording, given that a typical convective event rarely peaks exactly between two clock hours. This effect is more limited at the daily 
time scale, as the life cycle of convective events generally does not exceed a few hours and, generally, falls within a day.

- The signature of natural variability in terms of daily versus hourly trends may be quite different from the signature of the underlying climate change signal. In particular, it may only be for the latter (which is not yet emerging in the observations) where hourly trends are expected to exceed daily trends.

The (largely nonsignificant) increase in summer rainfall intensities over the last three decades is notable, and it may seem attractive to attribute this to thermodynamic (CC related) changes. However, the evidence presented here, coupled with previous research (e.g., Sutton and Dong 2012), suggests that natural variability, in part related to large-scale modes of variability such as the $\mathrm{NAO}$ and AMO, is an important driver of extreme rainfall in the United Kingdom. This is supported by Brown (2018), who showed that the NAO dominates observed trends in U.K. summer daily rainfall extremes, in this case using a different observational dataset (the $25-\mathrm{km}$ gridded dataset prepared for UKCP09 based on many more daily gauges). Otto et al. (2015) attributed an increased risk of July 5-day rainfall extremes (but not June or August extremes) for England and Wales to anthropogenic change and suggested that the AMO is not the most important driver of increased precipitation. This may have been due to deficiencies in the model used in their analysis or may indicate the need to investigate other possible drivers (e.g., Champion et al. 2015). Similarly, the increasing number of gauges displaying negative changes in winter, shown by the percentage change and running trend analyses, may be a consequence of a weakening of the positive phase of the NAO over recent decades, including a number of years when the NAO was in its negative phase toward the end of the analysis period. Such modes of variability may induce long-term persistence and further contribute to difficulties in identifying nonstationarity (Milly et al. 2015). Both change and trend analyses over these time scales are clearly sensitive to the period of record, and for precipitation, which may be highly variable on decadal and multidecadal time scales, care must be taken to consider the potential drivers of this variability rather than a casual inference of a potential climate change signal. A full attribution study is beyond the scope of this research, but this does highlight the need to consider the contribution of large-scale dynamical and thermodynamic drivers to observed changes and natural variability in precipitation extremes. Furthermore, while it has been proposed that adaptation planning and engineering design for infrastructure be guided by the CC relationship (Zhang et al. 2017), understanding of this scaling needs to be coupled with an understanding of large-scale drivers (e.g., Pfahl et al. 2017). This will lead not only to improved attribution of changes, but also to the improved use of models for seasonal predictions and long-term projections.

Notwithstanding these caveats, historical observations remain essential for a better understanding of change and will aid the development of better projections of the future (Montanari and Koutsoyiannis 2014; Milly et al. 2008), and there is a particular need to develop a global database for subdaily precipitation data (Zhang et al. 2017). However, quantified estimates of observed changes and trends in precipitation metrics are on their own unlikely to provide sufficient understanding of, and evidence for, human-induced change for some time, at least at local/regional scales across most parts of the globe for some of the reasons noted above. Robustly characterizing and attributing observed changes in subdaily extremes remains a considerable challenge. This is likely to be best addressed through the integrated use of high-quality historical observations, not only of relevant surface weather variables, but also of atmospheric variables, and through the application of process-based models (Lenderink and Fowler 2017), taking advantage of ongoing developments in convection-permitting climate modeling (Prein et al. 2015) and analysis at continental scales. These challenges are currently being addressed by the Intelligent Use of Climate Models for Adaptation to Nonstationary Hydrological Extremes (INTENSE) project. This project aims to establish increased synergy among data, models, and theory to enable the development of new downscaling approaches, using information from climate models and process understanding from observations in a more intelligent way. In doing so, we will be better able to understand how rainfall extremes will respond to a warmer world and the implications for adaptation strategies.

\section{Conclusions}

Results using output from a $1.5-\mathrm{km}$ convectionpermitting climate model over the southern United Kingdom indicate that changes to 10-min and 1-h precipitation emerge before changes to daily precipitation. In particular, the model results suggest detection times in the 2040s for hourly rainfall intensity in winter, which are 5-10 years earlier than for daily extremes. In summer, detection times are typically in the 2080s for heavy 10-min precipitation intensity, which is decades earlier than for daily extremes. However, there is considerable spatial variability in the detection time, particularly in 
summer. These results suggest that it is changes in rainfall rates, rather than changes to daily rainfall totals, which provide the greatest potential for detection of change. These could manifest in increases in pluvial flooding, which predominantly affect urban areas and small rapid-response catchments as flash floods. We note that it is in summer when the highest hourly precipitation extremes occur in the United Kingdom (Blenkinsop et al. 2017; Chan et al. 2014a). So even though we may be able to detect changes in precipitation extremes in winter first, the detection of changes in summer is of considerable practical value, particularly for the management of urban flash flooding. Hence, the considerably earlier emergence of short-duration extremes, compared to daily extremes, in summer is important.

Results from a new quality-controlled dataset of hourly rainfall over the United Kingdom do not show a similar difference between daily and hourly changes. This appears to be explained by natural variability dominating trends in current observational records, although as warming strengthens, the climate change signal may become more apparent. In general, the relative changes at hourly versus daily time scales may be a useful signature of underlying climate change that could be employed in detection and attribution studies. Although results presented here are for the United Kingdom, this signature is expected to apply more widely. In particular, where increasing atmospheric moisture with warming is the dominant driver of precipitation change, we may expect precipitation rates to intensify, as well as earlier emergence of detectable changes in shortduration precipitation intensities. There are also local feedbacks within storms, linked to latent heat release, which have been proposed to explain greater increases in rainfall extremes on hourly time scales (Lenderink and van Meijgaard 2010; Lenderink et al. 2017) and are expected to apply more generally in convective regimes and seasons. This is consistent with the model results here showing that it is in summer, in particular, when hourly and subhourly extremes emerge much sooner than daily ones, as this is the season when convective storms are more prevalent.

Providing robust quantitative estimates of when we may be able to detect the influence of climate change on rainfall extremes is important for informing adaptation planning. The results presented here are from a single realization of future climate change from one climate model, and so we have low confidence in the actual detection years quoted. Providing robust estimates of detection time will require additional CPM ensemble experiments that are currently planned over the United Kingdom as part of the UKCP18 project and, more widely, as part of coordinated multimodel projects (e.g., CORDEX-FPS).

Current guidance on climate change allowances for rainfall for the purposes of U.K. flood risk management is provided by Defra (Defra 2006) and the Environment Agency (Environment Agency 2011) and specifies peak rainfall intensity increases of 5\% (1990-2025), 10\% (2025$55), 20 \%(2055-85)$, and $30 \%(2085-2115)$ relative to a $1961-90$ baseline. However, this guidance is not designed to be applied to subdaily rainfall [the need for revised guidance is noted in Dale et al. (2017)]. Results here suggest separate climate change allowances need to be developed for hourly and subhourly rainfall, the latter being particularly important for urban flash flooding. Such allowances will need to be specified for changes emerging over the next few decades. Thus, future work will focus on exploiting the first ensemble of climate simulations at convection-permitting scale from UKCP18 to provide robust estimates of change in subdaily rainfall extremes to inform updated national guidance on climate change allowances.

Acknowledgments. E. J. Kendon gratefully acknowledges funding from the Joint UK BEIS/Defra Met Office Hadley Centre Climate Programme (GA01101). This work also forms part of a joint Met Office and Natural Environment Research Council (UKMO-NERC) funded project on Convective Extremes (CONVEX, NE/1006680/ 1) and the European Research Council funded INTENSE project (ERC-2013-CoG-617329). H. J. Fowler is also funded by the Wolfson Foundation and the Royal Society as a Royal Society Wolfson Research Merit Award (WM140025) holder. We thank Dr. Renaud Barbero for conducting the assessment of the statistical tests for break points and Dr. Steven Chan for contributing to the running of the climate model simulations.

\section{REFERENCES}

Agel, L., M. Barlow, J. H. Qian, F. Colby, E. Douglas, and T. Eichler, 2015: Climatology of daily precipitation and extreme precipitation events in the Northeast United States. J. Hydrometeor., 16, 2537-2557, https://doi.org/10.1175/ JHM-D-14-0147.1.

Allen, M. R., and W. J. Ingram, 2002: Constraints on future changes in climate and the hydrologic cycle. Nature, 419, 224-232, https://doi.org/10.1038/nature01092.

Archer, D. R., and H. J. Fowler, 2018: Characterising flash flood response to intense rainfall and impacts using historical information and gauged data in Britain. J. Flood Risk Manage., 11 (Suppl.), S121-S133, https://doi.org/10.1111/ jfr3.12187.

Arnbjerg-Nielsen, K., P. Willems, J. Olsson, S. Beecham, A. Pathirana, I. Bülow Gregersen, H. Madsen, and V. T. V. Nguyen, 2013: Impacts of climate change on rainfall extremes and urban drainage systems: A review. Water Sci. Technol., 68, 16-28, https://doi.org/10.2166/wst.2013.251. 
Barbero, R., H. J. Fowler, G. Lenderink, and S. Blenkinsop, 2017: Is the intensification of precipitation extremes with global warming better detected at hourly than daily resolutions? Geophys. Res. Lett., 43, 974-983, https://doi.org/10.1002/ 2016 GL071917.

Berg, P., C. Moseley, and J. O. Haerter, 2013: Strong increase in convective precipitation in response to higher temperatures. Nat. Geosci., 6, 181-185, https://doi.org/10.1038/ngeo1731.

Blenkinsop, S., S. C. Chan, E. J. Kendon, N. M. Roberts, and H. J. Fowler, 2015: Temperature influences on intense UK hourly precipitation and dependency on large-scale circulation. Environ. Res. Lett., 10, 054021, https://doi.org/10.1088/ 1748-9326/10/5/054021.

_ E. Lewis, S. C. Chan, and H. J. Fowler, 2017: Quality-control of an hourly rainfall dataset and climatology of extremes for the UK. Int. J. Climatol., 37, 722-740, https://doi.org/10.1002/joc.4735.

Brown, S., 2018: The drivers of variability in UK extreme rainfall. Int. J. Climatol., https://doi.org/10.1002/joc.5356.

Cabinet Office \& Defra, 2016: National Flood Resilience Review. HM Government, 145 pp., https://www.gov.uk/ government/uploads/system/uploads/attachment_data/file/ 551137/national-flood-resilience-review.pdf.

Champion, A. J., R. P. Allan, and D. A. Lavers, 2015: Atmospheric rivers do not explain UK summer extreme rainfall. J. Geophys. Res. Atmos., 120, 6731-6741, https://doi.org/ 10.1002/2014JD022863.

Chan, S. C., E. J. Kendon, H. J. Fowler, S. Blenkinsop, C. A. T. Ferro, and D. B. Stephenson, 2013: Does increasing the spatial resolution of a regional climate model improve the simulated daily precipitation? Climate Dyn., 41, 1475-1495, https://doi.org/ 10.1007/s00382-012-1568-9.

,,,,---- , and N. M. Roberts, 2014a: Projected increases in summer and winter UK sub-daily precipitation extremes from high-resolution regional climate models. Environ. Res. Lett., 9, 084019, https://doi.org/10.1088/1748-9326/ 9/8/084019.

, and C. A. T. Ferro, 2014b: The value of high-resolution Met Office regional climate models in the simulation of multihourly precipitation extremes. J. Climate, 27, 6155-6174, https://doi.org/10.1175/JCLI-D13-00723.1.

,,-- N. M. Roberts, H. J. Fowler, and S. Blenkinsop, 2016a: Downturn in scaling of UK extreme rainfall with temperature for future hottest days. Nat. Geosci., 9, 24-28, https://doi.org/ 10.1038/ngeo2596.

,,,---- , and,$- 2016 \mathrm{~b}$ : The characteristics of summer sub-hourly rainfall over the southern UK in a highresolution convective permitting model. Environ. Res. Lett., 11, 094024, https://doi.org/10.1088/1748-9326/11/9/094024.

Dale, M., B. Luck, H. J. Fowler, S. Blenkinsop, E. Gill, J. Bennett, E. J. Kendon, and S. C. Chan, 2017: New climate change rainfall estimates for sustainable drainage. Proc. IEEE, 170, 214-224, https://doi.org/10.1680/jensu.15.00030.

Darch, G. J. C., R. T. McSweeney, C. G. Kilsby, P. G. Jones, T. J. Osborn, and J. E. Tomlinson, 2016: Analysing changes in short-duration extreme rainfall events. Proc. IEEE, 169, 201211, https://doi.org/10.1680/jwama.14.00040.

Defra, 2006: Flood and Coastal Defence Appraisal Guidance FCDPAG3 economic appraisal: Supplementary note to operating authorities-Climate change impacts. Defra Rep., 9 pp., http://www.sdcg.org.uk/Climate-change-update.pdf.

Enfield, D. B., A. M. Mestas-Nuñez, and P. J. Trimble, 2001: The Atlantic multidecadal oscillation and its relation to rainfall and river flows in the continental U.S. Geophys. Res. Lett., 28 2077-2080, https://doi.org/10.1029/2000GL012745.

Environment Agency, 2011: Adapting to climate change: Advice for flood and coastal erosion risk management authorities. Environment Agency, 25 pp., https://www.gov.uk/ government/uploads/system/uploads/attachment_data/file/ 571572/LIT_5707.pdf.

Faulkner, D. S., 1999: Rainfall Frequency Estimation. Vol. 2, Flood Estimation Handbook, NERC Centre for Ecology \& Hydrology, $110 \mathrm{pp}$.

Fischer, E. M., and R. Knutti, 2016: Observed heavy precipitation increase confirms theory and early models. Nat. Climate Change, 6, 986-991, https://doi.org/10.1038/nclimate3110.

Folland, C. K., J. Knight, H. W. Linderholm, D. Fereday, S. Ineson, and J. W. Hurrell, 2009: The summer North Atlantic Oscillation: Past, present, and future. J. Climate, 22, 1082-1103, https://doi.org/10.1175/2008JCLI2459.1.

Fowler, H. J., and C. G. Kilsby, 2003a: A regional frequency analysis of United Kingdom extreme rainfall from 1961 to 2000. Int. J. Climatol., 23, 1313-1334, https://doi.org/10.1002/ joc. 943 .

- , and - 2003b: Implications of changes in seasonal and annual extreme rainfall. Geophys. Res. Lett., 30, 1720, https:// doi.org/10.1029/2003GL017327.

_ , and R. L. Wilby, 2010: Detecting changes in seasonal precipitation extremes using regional climate model projections: Implications for managing fluvial flood risk. Water Resour. Res., 46, W03525, https://doi.org/10.1029/2008WR007636.

—, D. Cooley, S. R. Sain, and M. Thurston, 2010: Detecting change in UK extreme precipitation using results from the climateprediction.net BBC Climate Change Experiment. Extremes, 13, 241-267, https://doi.org/10.1007/s10687-010-0101-y.

Hamlington, B. D., R. R. Leben, M. W. Strassburg, R. S. Nerem, and K.-Y. Kim, 2013: Contribution of the Pacific decadal oscillation to global mean sea level trends. Geophys. Res. Lett., 40, 5171-5175, https://doi.org/10.1002/grl.50950.

Hegerl, G. C., and Coauthors, 2015: Challenges in quantifying changes in the global water cycle. Bull. Amer. Meteor. Soc., 96, 1097-1115, https://doi.org/10.1175/BAMS-D-13-00212.1.

Hoy, A., A. Schucknecht, M. Sepp, and J. Matschullat, 2014: Largescale synoptic types and their impact on European precipitation. Theor. Appl. Climatol., 116, 19-35, https://doi.org/ 10.1007/s00704-013-0897-x.

Hurrell, J. W., 1995: Decadal trends in the North Atlantic Oscillation: Regional temperatures and precipitation. Science, $\mathbf{2 6 9}$, 676-679, https://doi.org/10.1126/science.269.5224.676.

_ 1996: Influence of variations in extratropical wintertime teleconnections on Northern Hemisphere temperature. Geophys. Res. Lett., 23, 665-668, https://doi.org/10.1029/ 96GL00459.

_ , and H. van Loon, 1997: Decadal variations in climate associated with the North Atlantic Oscillation. Climatic Change, 36, 301-326, https://doi.org/10.1023/A:1005314315270.

_ overview of the North Atlantic Oscillation. The North Atlantic Oscillation: Climatic Significance and Environmental Impact., Geophys. Monogr., Vol. 134, Amer. Geophys. Union, 1-35, https://doi.org/10.1029/134GM01.

Jassby, A. D., and J. E. Cloern, 2016: Some tools for exploring water quality monitoring data. R package version 0.4 .7 , https:// cran.r-project.org/src/contrib/Archive/wq/.

Jenkins, G. J., M. C. Perry, and J. Prior, 2008: The climate of the United Kingdom and recent trends. Met Office Hadley 
Centre, 122 pp., http://www.ukcip.org.uk/wp-content/PDFs/ UKCP09_Trends.pdf.

Jones, M. R., H. J. Fowler, C. G. Kilsby, and S. Blenkinsop, 2013: An assessment of changes in seasonal and annual extreme rainfall in the UK between 1961 and 2009. Int. J. Climatol., 33, 1178-1194, https://doi.org/10.1002/joc.3503.

Jones, P. D., T. Jónsson, and D. Wheeler, 1997: Extension to the North Atlantic Oscillation using early instrumental pressure observations from Gibraltar and south-west Iceland. Int. J. Climatol., 17, 1433-1450, https://doi.org/10.1002/(SICI)1097-0088(19971115)17: $13<1433:: A I D-J O C 203>3.0 . C O ; 2-P$

Kendon, E. J., N. M. Roberts, C. A. Senior, and M. J. Roberts, 2012: Realism of rainfall in a very high-resolution regional climate model. J. Climate, 25, 5791-5806, https://doi.org/ 10.1175/JCLI-D-11-00562.1.

- - - H. J. Fowler, M. J. Roberts, S. C. Chan, and C. A. Senior, 2014: Heavier summer downpours with climate change revealed by weather forecast resolution model. Nat Climate Change, 4, 570-576, https://doi.org/10.1038/nclimate2258. _ , and Coauthors, 2017:Do convection-permitting regional climate models improve projections of future precipitation change? Bull. Amer. Meteor. Soc., 98, 79-93, https://doi.org/ 10.1175/BAMS-D-15-0004.1.

Lean, H. W., P. A. Clark, M. Dixon, N. M. Roberts, A. Fitch, R. Forbes, and C. Halliwell, 2008: Characteristics of highresolution versions of the Met Office Unified Model for forecasting convection over the United Kingdom. Mon. Wea. Rev., 136, 3408-3424, https://doi.org/10.1175/ 2008MWR2332.1.

Lenderink, G., and E. van Meijgaard, 2008: Increase in hourly precipitation extremes beyond expectations from temperature changes. Nat. Geosci., 1, 511-514, https://doi.org/10.1038/ ngeo262.

—, and - 2010: Linking increases in hourly precipitation extremes to atmospheric temperature and moisture changes. Environ. Res. Lett., 5, 025208, https://doi.org/10.1088/1748-9326/ 5/2/025208.

- and H. J. Fowler, 2017: Hydroclimate: Understanding rainfall extremes. Nat. Climate Change, 7, 391-393, https://doi.org/ 10.1038/nclimate3305.

— R. Barbero, J. M. Loriaux, and H. J. Fowler, 2017: SuperClausius-Clapeyron scaling of extreme hourly convective precipitation and its relation to large-scale atmospheric conditions. J. Climate, 30, 6037-6052, https://doi.org/10.1175/ JCLI-D-16-0808.1.

Linderholm, H. W., C. K. Folland, and A. Walther, 2009: A multicentury perspective on the summer North Atlantic Oscillation (SNAO) and drought in the eastern Atlantic region. J. Quat. Sci., 24, 415-425, https://doi.org/10.1002/jqs.1261.

Lohmann, K., H. Drange, and M. Bentsen, 2009: Response of the North Atlantic subpolar gyre to persistent North Atlantic Oscillation like forcing. Climate Dyn., 32, 273-285, https://doi.org/ 10.1007/s00382-008-0467-6.

Loriaux, J. M., G. Lenderink, S. R. De Roode, and A. P. Siebesma, 2013: Understanding convective extreme precipitation scaling using observations and an entraining plume model. J. Atmos. Sci., 70, 3641-3655, https://doi.org/10.1175/JAS-D-12-0317.1.

Malby, A. R., J. D. Whyatt, R. J. Timmis, R. L. Wilby, and H. G. Orr, 2007: Long-term variations in orographic rainfall: Analysis and implications for upland catchments. Hydrol. Sci. J., 52, 276-291, https://doi.org/10.1623/hysj.52.2.276.

Maraun, D., T. J. Osborn, and N. P. Gillett, 2008: United Kingdom daily precipitation intensity: Improved early data, error estimates and an update from 2000 to 2006. Int. J. Climatol., 28, 833-842, https://doi.org/10.1002/joc.1672.

Milly, P. C. D., J. Betancourt, M. Falkenmark, R. M. Hirsch, Z. W. Kundzewicz, D. P. Lettenmaier, and R. J. Stouffer, 2008: Stationarity is dead: Whither water management? Science, 319, 573-574, https://doi.org/10.1126/science.1151915.

, and Coauthors, 2015: On critiques of "Stationarity is dead: Whither water management?" Water Resour. Res., 51, 77857789, https://doi.org/10.1002/2015WR017408.

Min, S.-K., X. Zhang, F. W. Zwiers, and G. C. Hegerl, 2011: Human contribution to more-intense precipitation extremes. Nature, 470, 378-381, https://doi.org/10.1038/nature09763.

Mishra, V., J. M. Wallace, and D. P. Lettenmaier, 2012: Relationship between hourly extreme precipitation and local air temperature in the United States. Geophys. Res. Lett., 39, L16403, https://doi.org/10.1029/2012GL052790.

Montanari, A., and D. Koutsoyiannis, 2014: Modeling and mitigating natural hazards: Stationarity is immortal! $W a$ ter Resour. Res., 50, 9748-9756, https://doi.org/10.1002/ 2014WR016092.

Murphy, J. M., and Coauthors, 2009: UK Climate Projections science report: Climate change projections. Met Office Hadley Centre Rep., 10 pp., http://ukclimateprojections.metoffice.gov.uk/ media.jsp?mediaid $=87893$.

Osborn, T. J., and M. Hulme, 2002: Evidence for trends in heavy rainfall events over the UK. Philos. Trans. Roy. Soc. London, 360, 1313-1325, https://doi.org/10.1098/ rsta.2002.1002.

$\longrightarrow,-$ P. D. Jones, and T. A. Basnett, 2000: Observed trends in the daily intensity of United Kingdom precipitation. Int. J. Climatol., 20, 347-364, https://doi.org/10.1002/(SICI)1097-0088(20000330)20: 4<347::AID-JOC475>3.0.CO;2-C.

Otto, F. E. L., S. M. Rosier, M. R. Allen, N. R. Massey, C. J. Rye, and J. I. Quintana, 2015: Attribution analysis of high precipitation events in summer in England and Wales over the last decade. Climatic Change, 132, 77-91, https://doi.org/ 10.1007/s10584-014-1095-2.

Pall, P., M. R. Allen, and D. A. Stone, 2007: Testing the ClausiusClapeyron constraint on changes in extreme precipitation under $\mathrm{CO}_{2}$ warming. Climate Dyn., 28, 351-363, https://doi.org/ 10.1007/s00382-006-0180-2.

, T. Aina, D. A. Stone, P. A. Stott, T. Nozawa, A. G. J. Hilberts, D. Lohmann, and M. R. Allen, 2011: Anthropogenic greenhouse gas contribution to flood risk in England and Wales in autumn 2000. Nature, 470, 382-385, https://doi.org/ 10.1038/nature09762.

Pfahl, S., P. A. O'Gorman, and E. M. Fischer, 2017: Understanding the regional pattern of projected future changes in extreme precipitation. Nat. Climate Change, 7, 423-427, https://doi.org/ 10.1038/nclimate3287.

Prein, A. F., and Coauthors, 2015: A review on regional convection-permitting climate modeling: Demonstrations, prospects, and challenges. Rev. Geophys., 53, 323-361, https:// doi.org/10.1002/2014RG000475.

Risbey, J. S., S. Lewandowsky, C. Langlais, D. P. Monselesan, T. J. O'Kane, and N. Oreskes, 2014: Well-estimated global surface warming in climate projections selected for ENSO phase. Nat. Climate Change, 4, 835-840, https://doi.org/ 10.1038/nclimate2310.

Robson, J., R. Sutton, K. Lohmann, D. Smith, and M. D. Palmer, 2012: Causes of the rapid warming of the North Atlantic Ocean in the mid-1990s. J. Climate, 25, 4116-4134, https://doi.org/ 10.1175/JCLI-D-11-00443.1. 
Santer, B. D., and Coauthors, 2014: Volcanic contribution to decadal changes in tropospheric temperature. Nat. Geosci., 7, 185-189, https://doi.org/10.1038/ngeo2098.

Sarojini, B. B., P. A. Stott, and E. Black, 2016: Detection and attribution of human influence on regional precipitation. Nat. Climate Change, 6, 669-675, https://doi.org/10.1038/ nclimate2976.

Schaller, N., and Coauthors, 2016: Human influence on climate in the 2014 southern England winter floods and their impacts. Nat. Climate Change, 6, 627-634, https://doi.org/10.1038/nclimate2927.

Sen, P. K., 1968: Estimates of the regression coefficient based on Kendall's tau. J. Amer. Stat. Assoc., 63, 1379-1389, https://doi.org/ 10.1080/01621459.1968.10480934.

Simpson, I. R., and P. D. Jones, 2014: Analysis of UK precipitation extremes derived from Met Office gridded data. Int. J. Climatol., 34, 2438-2449, https://doi.org/10.1002/joc.3850.

Stein, T. H. M., R. J. Hogan, P. A. Clark, C. E. Halliwell, K. E. Hanley, H. W. Lean, J. C. Nicol, and R. S. Plant, 2015: The DYMECS project: A statistical approach for the evaluation of convective storms in high-resolution NWP models. Bull. Amer. Meteor. Soc., 96, 939-951, https://doi.org/10.1175/ BAMS-D-13-00279.1.

Sutton, R. T., and B. Dong, 2012: Atlantic Ocean influence on a shift in European climate in the 1990s. Nat. Geosci., 5, 788792, https://doi.org/10.1038/ngeo1595.

Theil, H., 1950a: A rank-invariant method of linear and polynomial regression analysis: I. Nederl. Akad. Wetensch. Proc., 53, 386-392.

_ $1950 \mathrm{~b}$ : A rank-invariant method of linear and polynomial regression analysis: II. Nederl. Akad. Wetensch. Proc., 53, 521-525.

- 1950c: A rank-invariant method of linear and polynomial regression analysis: III. Nederl. Akad. Wetensch. Proc., 53, 1397-1412.

Trenberth, K. E., A. Dai, R. M. Rasmussen, and D. B. Parsons, 2003: The changing character of precipitation. Bull. Amer. Meteor. Soc., 84, 1205-1217, https://doi.org/10.1175/ BAMS-84-9-1205.
Trigo, R. M., T. J. Osborn, and J. Corte-Real, 2002: The North Atlantic Oscillation influence on Europe: Climate impacts and associated physical mechanisms. Climate Res., 20, 9-17, https://doi.org/10.3354/cr020009.

Trottini, M., M. Isabel, V. Aguiar, and S. B. Palazón, 2015: On the use of running trends as summary statistics for univariate time series and time series association. J. Climate, 28, 7489-7502, https://doi.org/10.1175/JCLI-D-15-0009.1.

Walker, G. T., 1924: Correlations in seasonal variations of weather. IX: A further study of world weather. Mem. Indian Meteor. Dept., 24, 275-333.

Walters, D. N., and Coauthors, 2011: The Met Office Unified Model Global Atmosphere 3.0/3.1 and JULES Global Land 3.0/3.1 configurations. Geosci. Model Dev., 4, 919-941, https:// doi.org/10.5194/gmd-4-919-2011.

Wasko, C., A. Sharma, and S. Westra, 2016: Reduced spatial extent of extreme storms at higher temperatures. Geophys. Res. Lett., 43, 4026-4032, https://doi.org/10.1002/2016GL068509.

Westra, S., and S. A. Sisson, 2011: Detection of non-stationarity in precipitation extremes using a max-stable process model. J. Hydrol., 406, 119-128, https://doi.org/10.1016/j.jhydrol.2011.06.014.

— frequency of short-duration extreme rainfall. Rev. Geophys., 52, 522-555, https://doi.org/10.1002/2014RG000464.

Wilby, R. L., G. O'Hare, and N. Barnsley, 1997: The North Atlantic Oscillation and British Isles climate variability, 1865-1996. Weather, 52, 266-276, https://doi.org/10.1002/ j.1477-8696.1997.tb06323.x.

_ D. Conway, and P. D. Jones, 2002: Prospects for downscaling seasonal precipitation variability using conditioned weather generator parameters. Hydrol. Processes, 16, 1215-1234, https://doi.org/10.1002/hyp.1058.

Zhang, X., F. W. Zwiers, G. Li, H. Wan, and A. J. Cannon, 2017: Complexity in estimating past and future extreme shortduration rainfall. Nat. Geosci., 10, 255-259, https://doi.org/ 10.1038/ngeo2911. 